Article

\title{
Selective Binding, Self-Assembly and Nanopatterning of the Creutz-Taube Ion on Surfaces
}

\author{
Yuliang Wang ${ }^{1, *}$, Marya Lieberman ${ }^{1}$, Qingling Hang ${ }^{2}$ and Gary Bernstein ${ }^{2}$
}

1 Department of Chemistry, University of Notre Dame, Notre Dame, Indiana 46556, USA;

E-Mail: mlieberm@nd.edu

2 Department of Electric Engineering, University of Notre Dame, Notre Dame, Indiana 46556, USA; E-Mails: qhang@nd.edu (Q.H.); gbernste@nd.edu (G.B.)

\footnotetext{
* Author to whom correspondence should be addressed; E-mail: yuliangwang@gmail.com
}

Received: 3 December 2008; in revised form: 7 February 2009 / Accepted: 11 February 2009 /

Published: 12 February 2009

\begin{abstract}
The surface attachment properties of the Creutz-Taube ion, i.e., $\left[\left(\mathrm{NH}_{3}\right)_{5} \mathrm{Ru}(\text { pyrazine }) \mathrm{Ru}\left(\mathrm{NH}_{3}\right)_{5}\right]^{5+}$, on both hydrophilic and hydrophobic types of surfaces were investigated using X-ray photoelectron spectroscopy (XPS). The results indicated that the Creutz-Taube ions only bound to hydrophilic surfaces, such as $\mathrm{SiO}_{2}$ and $-\mathrm{OH}$ terminated organic SAMs on gold substrates. No attachment of the ions on hydrophobic surfaces such as $-\mathrm{CH}_{3}$ terminated organic SAMs and poly(methylmethacrylate) (PMMA) thin films covered gold or $\mathrm{SiO}_{2}$ substrates was observed. Further ellipsometric, atomic force microscopy (AFM) and time-dependent XPS studies suggested that the attached cations could form an inorganic analog of the self-assembled monolayer on $\mathrm{SiO}_{2}$ substrate with a "lying-down" orientation. The strong electrostatic interaction between the highly charged cations and the anionic $\mathrm{SiO}_{2}$ surface was believed to account for these observations. Based on its selective binding property, patterning of wide ( $200 \mathrm{~nm})$ and narrow $(\sim 35 \mathrm{~nm})$ lines of the Creutz-Taube ions on $\mathrm{SiO}_{2}$ surface were demonstrated through PMMA electron resist masks written by electron beam lithography (EBL).
\end{abstract}

Keywords: Creutz-Taube ions; Surface; Hydrophilic; Hydrophobic; XPS; AFM; Selfassembled Monolayers; E-beam lithography; PMMA; Nanopatterning. 


\section{Introduction}

The preparation of organized monolayer and multilayer molecular assemblies on solid substrates has been an area of great interest for many years due to their important roles in various applications such as catalysis [1], electrochemistry [2-5], microelectronics [6-8], and especially, in the recently upand-coming areas of nanotechnology [9] and biotechnology [10]. Various techniques can be used to place molecules on surfaces, such as Langmuir-Blodgett deposition [11,12], spin-coating [13,14], and vapor deposition $[15,16]$. Compared with these techniques, the self-assembled monolayer (SAM) technique developed by Whitesides, Ulman and Nuzzo [17-19] offers great advantages in that the monolayer films are normally formed through adsorption from solution and are chemically bound to substrates so that reproducible and stable films can be easily obtained. By choosing different types of functional head and tail groups for the SAM molecules, the interaction between these end groups and the substrates could be adjusted to be highly specific and often involve the formation of strong covalent bonds (e.g., thiols on gold, siloxanes on $\mathrm{SiO}_{2}$, isocyanates on platinum, carboxylates on alumina, vinyl groups on hydrogen terminated silicon, etc) [17]. With the deposition of SAMs containing different functional groups on the substrates, the surface chemistry of solid substrates could be modified accordingly. Although most of the previous studies on SAMs are related to the formation of organic monolayers that are covalently-bonded to the substrates, there are also a number of studies dealing with the SAMs that were formed through electrostatic or ionic interactions between the charged adsorbates and the substrates [20-32], i.e., an inorganic analog of the self-assembled organic monolayers. With the selective binding property between oppositely charged adsorbates and substrates and also the possibility of forming hydrogen bond between the electron donor groups and $\mathrm{OH}$ or $\mathrm{NH}_{2}$ groups, molecular patterning [33-41], bioreorganization [42-47] and sequential layer-by-layer deposition [48-50] have been demonstrated in a number of previous studies on various types of inorganic SAMs.

For a recently proposed and developed novel computational architecture, quantum-dot cellular automata (QCA) [51-54], the well-known mixed-valence Creutz-Taube ion [55-58], i.e., $\left[\left(\mathrm{NH}_{3}\right)_{5} \mathrm{Ru}(\text { pyrazine }) \mathrm{Ru}\left(\mathrm{NH}_{3}\right)_{5}\right]^{5+}$, has been selected as a prospective candidate molecule for the implementation of QCA at a molecular scale [59-61]. In the QCA paradigm, the candidate molecules will have to be patterned into arrayed structures to carry out logical computing [51-54]. To achieve this, a proper substrate is necessary to put the molecules on and then to pattern them. Here we are interested in knowing whether the Creutz-Taube ions have the required selective binding properties (for surface patterning) on different types of surfaces, such as hydrophilic versus hydrophobic; and if they do bind, whether they can form a self-assembled inorganic monolayer on the substrate.

Some studies have been done to investigate the surface attachment properties of several ruthenium compounds on modified surfaces where different anchoring groups were used [62-66]. For example, Isied and coworkers have demonstrated the binding of trans-[Ru(II) $\left.\left(\mathrm{NH}_{3}\right)_{4}\left(\mathrm{H}_{2} \mathrm{O}\right)_{2}\right]$ to terminal pyridine or imidazole groups on self-assembled monolayers [67]. In many cases, it has been found that the organic SAM can confer control over the orientation of the adsorbed inorganic molecules, which argues for strong interactions between the SAM surface and the inorganic molecules layer.

In this study, two types of surfaces, i.e., $-\mathrm{OH}$ group terminated hydrophilic surfaces and $-\mathrm{CH}_{3}$ group terminated hydrophobic surfaces, were used to study the selective binding properties of the 
Creutz-Taube ions. X-ray photoelectron spectroscopy (XPS) was the main technique used in this study to detect the binding of the molecules on surfaces. XPS can easily detect an impurity atom on a surface, even when the surface coverage is only about one in one hundred substrate atoms. With this sensitivity the selective binding of the Creutz-Taube ions on surface could easily be observed. Silicon [100] wafers covered with a freshly grown native oxide were used as the hydrophilic substrate for our initial binding study. The existence of silanol groups ( $\mathrm{Si}-\mathrm{OH})$ on silica surfaces was first postulated by Hofman in 1934 [68]. Various analytical techniques have allowed silica scientists later to confirm and expand the view of the silica surface in terms of silanol groups, siloxane bridges, and hydrogenbonded water [68]. It is now generally accepted that surface silicon atoms tend to have a complete tetrahedral configuration and that in an aqueous medium their free valence becomes saturated with hydroxyl groups and form silanol groups with a density of $\mathrm{SiOH}$ on $\mathrm{SiO}_{2} \sim 4.6-\mathrm{OH} / \mathrm{nm}^{2}$ [68]. Besides $\mathrm{SiO}_{2}$, another way to prepare a hydrophilic surface is to grow SAMs terminated with $-\mathrm{OH}$ or some other hydrophilic functional groups such as $\mathrm{NH}_{2}$ and $-\mathrm{PO}_{3} \mathrm{H}_{2}$ onto the substrates. Here $-\mathrm{OH}$ terminated hydroxyundecanethiol (HUT) was used in this study to form a hydrophilic monolayer on gold substrate. Similarly, $-\mathrm{CH}_{3}$ terminated octadecyltrichlorosilane (OTS) and octadecanethiol (ODT) were used to form hydrophobic surfaces on $\mathrm{SiO}_{2}$ and gold substrates respectively. For surface patterning purpose, the binding of the Creutz-Taube ions on another hydrophobic surface - poly(methyl methacrylate) (PMMA) covered $\mathrm{SiO}_{2}$, was investigated as well. Besides XPS, ellipsometry measurement and atomic force microscopy (AFM) were also used to track monolayer formation and characterize the adsorbed species. Our results indicated that the Creutz-Taube ions only bound to hydrophilic surfaces, such as $\mathrm{SiO}_{2}$ and $-\mathrm{OH}$ terminated organic SAMs, but not to hydrophobic surfaces, such as OTS and ODT SAMs or PMMA thin film. The counter ions of the Creutz-Taube ions, either toluenesulfonate (TOS) or hexfluorophosphate $\left(\mathrm{PF}_{6}\right)$ as used in this study, were not observed on any of the two types of surfaces. Additional experimental results also suggested that the attached Creutz-Taube ions could form a self-limiting monolayer on $\mathrm{SiO}_{2}$ with a "lying-down" orientation. Because of its selective-binding property, patterning of wide $(\sim 200 \mathrm{~nm})$ and narrow $(\sim 35$ $\mathrm{nm}$ ) lines of the Creutz-Taube ions on $\mathrm{SiO}_{2}$ surface were demonstrated through PMMA masks written by electron beam lithography (EBL).

\section{Experimental Section}

\subsection{Chemicals and Materials}

The Creutz-Taube ions used in this study were prepared using published procedures and were precipitated and thus collected with either $p$-toluenesulfonate (TOS) or hexafluorophosphate $\left(\mathrm{PF}_{6}\right)$ as their counter ions [55-58]. Octadecyltrichlorosilane (OTS), octadecanethiol (ODT), 11-mercapto undecanol (HUT) were received from Aldrich and used without further purification. P-doped singlesided polished Si wafers (100 orientation) were obtained from MEMC Electronic Materials, Inc. Gold wire (99.99\%) was obtained from Aldrich, and mica sheet was from Woodman Associates, Inc. Other solvents were used directly as received. 


\subsection{Substrate Preparation}

The preparation of Si substrates covered with freshly grown native oxide or ultrasmooth complete OTS monolayer followed a previously described procedure [69]. Gold substrates were prepared by evaporating $\sim 800 \AA$ of gold onto freshly cleaved mica sheets using a Ladd evaporator (Ladd Research Industries Inc.) under a vacuum of $10^{-6}$ Torr. The gold evaporation rate was kept at $0.6 \AA / \mathrm{s}$. The surfaces were annealed in a hydrogen flame immediately before immersion in derivatization solutions. This annealing step cleans the surface and allows epitaxial reconstruction of the Au to form large terraces of $\mathrm{Au}$ [111]. Self-assembled monolayers of alkanethiols on gold with terminal $-\mathrm{CH}_{3}$ and $-\mathrm{OH}$ functional groups were prepared by soaking gold substrates (cut to $1 \mathrm{~cm} \times 1 \mathrm{~cm}$ ) in $1 \mathrm{mM}$ solution of ODT or HUT in chloroform overnight. Upon removal from the solution, the samples were washed thoroughly with chloroform and then blown dry with nitrogen. The HUT covered gold substrate showed contact angles under $20^{\circ}$ and an ellipsometric thickness of $13.8 \pm 0.4 \AA$ confirming the selfassembled monolayer formation on the substrate. For ODT covered gold substrate, the value of $115 \pm 5^{\circ}$ was obtained in the contact angle measurement indicating the expected hydrophobicity of the surface.

\subsection{Surface Attachment of the Creutz-Taube ions on substrates}

A concentration of $0.5 \mathrm{mM}$ Creutz-Taube ion in DI water was used. In typical preparations, the substrates were soaked in the solution for three hours in a dark environment. Running DI water was used for final rinsing before the samples were blown dry with a strong flow of nitrogen.

\subsection{Electron Beam Lithography Patterning of the Creutz-Taube Ions}

Oxidized $\mathrm{Si}$ wafers $\left(\sim 100 \mathrm{~nm}\right.$ thick $\mathrm{SiO}_{2}$ on an n-type silicon formed by dry oxidation at $1200^{\circ} \mathrm{C}$ for one hour) were cleaned prior to spinning coating of PMMA. First, the oxidized wafers were ultrasonicated in trichloroethylene and acetone for $10 \mathrm{~min}$ each, rinsed in DI water; soaked in a "RCA1" bath at $75{ }^{\circ} \mathrm{C}$ for $15 \mathrm{~min}$, then soaked in a "RCA2" bath at $75{ }^{\circ} \mathrm{C}$ for $15 \mathrm{~min}$, and finally soaked in 1:10 HF solution for $10 \mathrm{~s}$ and rinsed in DI water. The wafers were baked at $180{ }^{\circ} \mathrm{C}$ for $5 \mathrm{~min}$ on a hot plate to drive off moisture from the surface. The resulting surface oxide was estimated to be about 90 -nm-thick. A 30-nm-thick layer of $950 \mathrm{kDa}$ PMMA was spun on and baked at $180{ }^{\circ} \mathrm{C}$ for 3 min. Finally, high-resolution patterns were exposed in our customized EBL system (modified from an Amray $1400 \mathrm{SEM}$ ) at a beam current of $10 \mathrm{pA}$ and acceleration voltage of $50 \mathrm{keV}$. After EBL exposure, the wafer was soaked in developer [1:3 methyl isobutyl ketone: 2-propanol (IPA) with 1.5\% methyl ethyl ketone] for $30 \mathrm{~s}$, and then rinsed with IPA, resulting in trenches in the PMMA film exposing portions of the $\mathrm{SiO}_{2}$ surface. After drying with $\mathrm{N}_{2}$, the wafer was soaked in $5 \mathrm{mM}$ aqueous solution of the Creutz-Taube ions for $3 \mathrm{~h}$, then rinsed with DI water and blown dry. Acetone or dichloromethane (DCM) was used to remove the unexposed PMMA. 


\subsection{XPS measurement}

X-ray photoelectron spectroscopy (XPS) was done using a Kratos XSAM 800 with an Al Ka X-ray source $(1486.6 \mathrm{eV})$. The takeoff angle was fixed at $90^{\circ}$. The samples were mounted on sample stubs with conductive carbon tape. All peaks were fitted with Gauss-Lorentz peaks using the Kratos Vision II software to obtain peak area information. A linear base line was used in the fitting processes.

\subsection{Ellipsometric Measurement}

The thicknesses of the Creutz-Taube ions on $\mathrm{SiO}_{2}$ substrate were obtained using an Rudolph AutoEl III ellipsometer. First, the thickness of the thin native oxide layer on a cleaned native $\mathrm{SiO}_{2} \mathrm{substrate}$ was measured. Then after soaking the substrate in $5 \mathrm{mM}$ solution of the Creutz-Taube ion for more than three hours, the sample was rinsed with copious running water and blown dry with a strong flow of nitrogen. The measurement was performed using $632.8 \mathrm{~nm} \mathrm{He} / \mathrm{Ne}$ laser light incident upon the sample at $70^{\circ}$. Both a single-layer and double-layer models were used to verify the validity of the thickness measurement. For each sample, the measurement was done at several places on the surface and the results were averaged. A refractive index of 1.46 was assumed for the $\mathrm{SiO}_{2}$ surface [68] and 1.50 for the Creutz-Taube $\mathrm{SAMs}$ on $\mathrm{SiO}_{2}$ surface [17].

\subsection{Contact Angle Measurement}

All measurements of contact angles are advancing angles and were performed with a KRUSS G 10 contact angle instrument. On each sample at least four different locations were measured and results were averaged.

\subsection{AFM Measurement}

AFM was carried out using a Digital Instruments (Santa Barbara, CA) Multimode Nanoscope III instrument operating in tapping mode. The tips used were tapping mode etched silicon probes (Olympus) with a tip radius of $15-35 \mathrm{~nm}$. The imaging setpoint was set for $1.5 \mathrm{~V}$. Image analysis was performed offline using roughness and section commands provided in the AFM software.

\section{Results and Discussion}

\subsection{XPS Measurements on Bare Substrates and Bulk Powder Samples as Control Experiments}

Before we carried out the surface attachment studies on the Creutz-Taube ions, as a control experiment, all of the bare substrates (both hydrophilic and hydrophobic) were first checked by XPS to ensure there was no $\mathrm{N}, \mathrm{Ru}$, or $\mathrm{S}$ on the surface. As a typical example, Figure 1 gives the result of an XPS measurement for $\mathrm{Ru} 3 \mathrm{p}, \mathrm{Ru} 3 \mathrm{~d}, \mathrm{~N} 1 \mathrm{~s}$ and $\mathrm{Si} 2 \mathrm{p}$ region on a bare $\mathrm{SiO}_{2}$ substrate, from which we may clearly see that no nitrogen or ruthenium was observed. Here all peaks were fitted with Gauss- 
Lorentz peaks using the Kratos Vision II software to obtain peak area information. A linear base line was used in the peak fitting processes.

Figure 1. XPS spectra of a bare $\mathrm{SiO}_{2}$ substrate before soaking in the Creutz-Taube ion solution. Shown in (A), (B), (C), and (D) are the XPS regions corresponding to element components of Ru 3p, Ru 3d, N 1s and Si 2p, respectively.
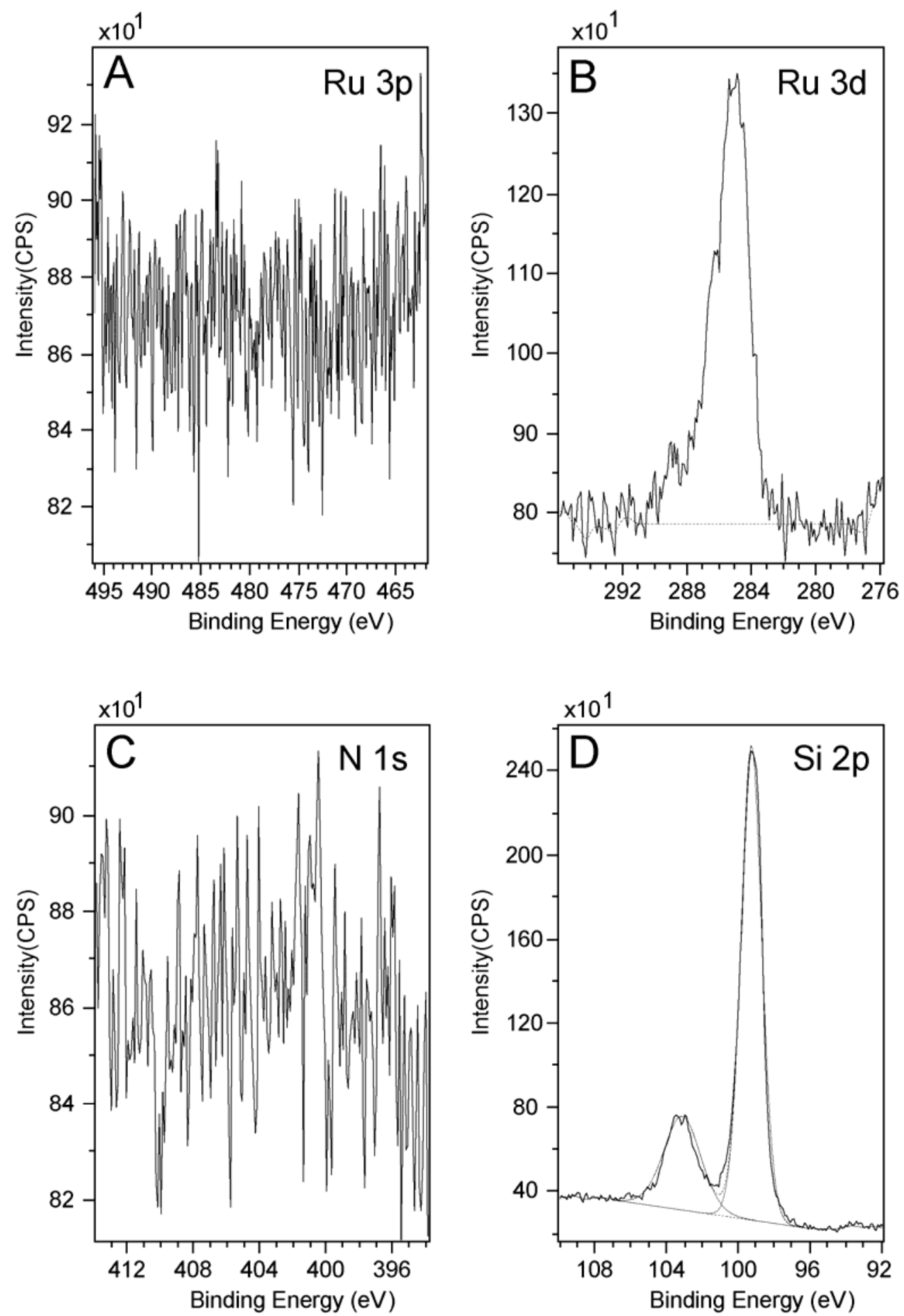
The peak centered at $284.5 \mathrm{eV}$, as shown in the $\mathrm{Ru} 3 \mathrm{~d}$ region (Figure 1B), is in fact the $\mathrm{C}$ 1s peak originating from a large amount of adventitious carbon. For $\mathrm{Ru} 3 \mathrm{~d}$, we would expect two peaks in the region of $284 \mathrm{eV} \sim 286 \mathrm{eV}$ and $280 \mathrm{eV} \sim 282 \mathrm{eV}$ which correspond to spin $3 \mathrm{~d}^{3 / 2}$ and $3 \mathrm{~d}^{5 / 3}$ respectively [70-73]. Here we see no peak corresponding to $3 \mathrm{~d}^{5 / 3}$ in the latter region in Figure $1 \mathrm{~B}$. In another control experiment, a powder sample of the Creutz-Taube ion with toluenesulfonate (TOS) as its counter ion was also prepared and measured using XPS. Figure 2 gives the corresponding results for a survey scan and high resolution scans at specific regions. The peaks of $\mathrm{Ru}(3 \mathrm{p}, 3 \mathrm{~d})$ and $\mathrm{N}(1 \mathrm{~s})$ from the Creutz-Taube cations and $S(2 p)$ from the anion are seen in this figure, as expected.

Figure 2. XPS spectra of a powder sample of the Creutz-Taube ions, with (TOS) ${ }^{-}$as the counter ions. Shown in (A), (B), (C), and (D) are the XPS regions corresponding to element components of Ru 3d, N 1s, Ru $3 p$ and $S 2 p$, respectively.
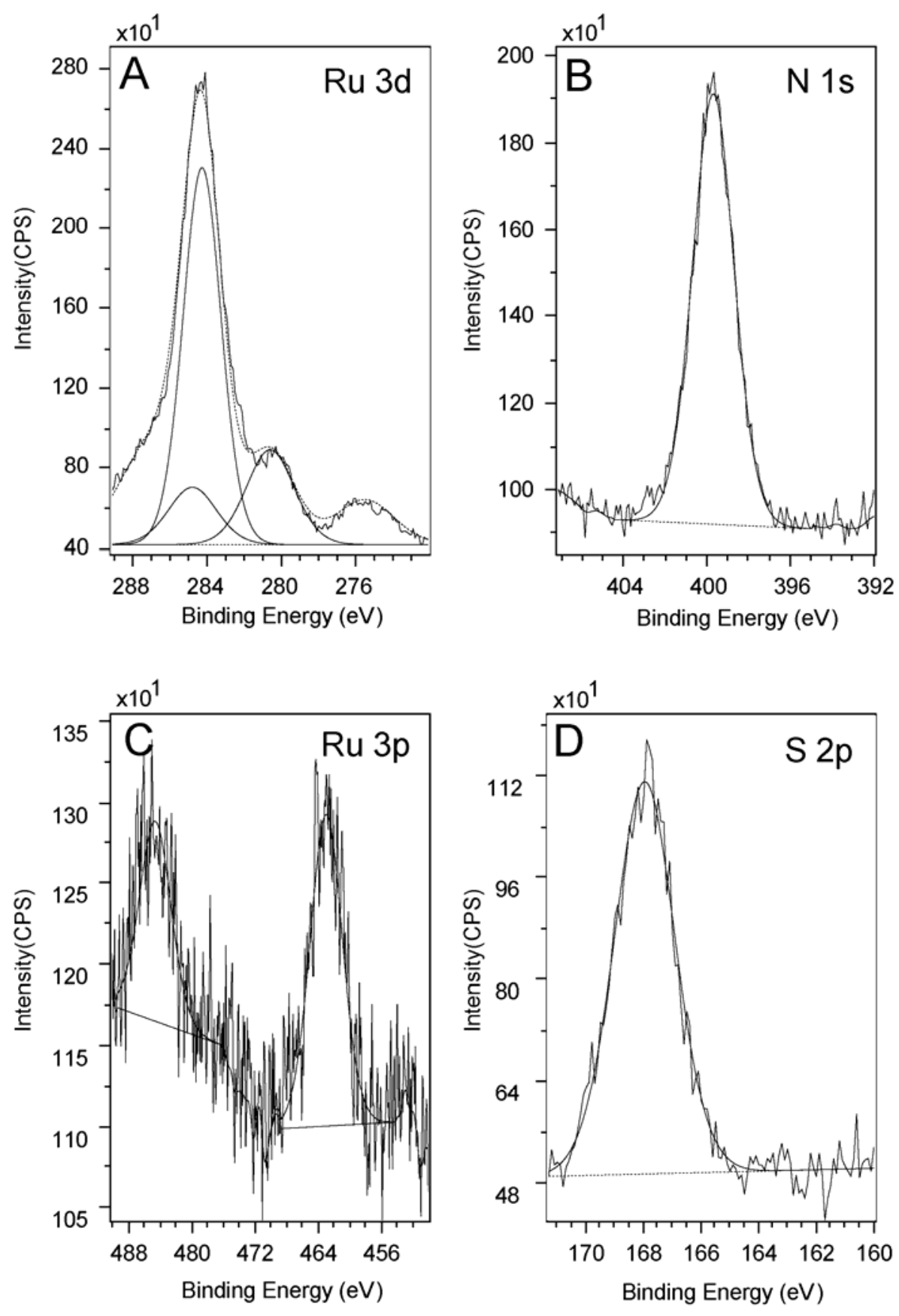
Due to the limited conductivity associated with the sample, charge accumulation caused about a 2 $\mathrm{eV}$ binding energy shift. The conventional method of calibration using the $\mathrm{C} 1 \mathrm{~s}$ peak of adventitious carbon at $284.5 \mathrm{eV}$ was used for the powder sample. For $\mathrm{Ru} 3 \mathrm{~d}$, because of its overlapping with the intense $\mathrm{C} 1 \mathrm{~s}$ peak, only the $3 \mathrm{~d}^{5 / 2}$ peak is observed at $280.5 \mathrm{eV}$, the $\mathrm{Ru} 3 \mathrm{~d}^{3 / 2}$ component is buried under the $\mathrm{C} 1 \mathrm{~s}$ peak at $284.5 \mathrm{eV}$ and is not clearly resolved in our spectra. Here it was fitted as a peak about $69 \%$ area of that of the $\mathrm{Ru} 3 \mathrm{~d}^{5 / 2}$ component and with a spin orbit splitting of $4.1 \mathrm{eV} \mathrm{[70-73]}$. For $\mathrm{Ru} 3 \mathrm{p}$, two peaks with the binding energy of $461.8 \mathrm{eV}$ and $484.7 \mathrm{eV}$ corresponding to spin $3 / 2$ and $1 / 2$ are observed. The N 1s peak appears at $399.7 \mathrm{eV}$ as shown in Figure 2B. In the Creutz-Taube ion, there are two nitrogen sources, one is from the $\mathrm{NH}_{3}$ groups and the other one is from the pyrazine group. Since both types of nitrogen are connected to the ruthenium atoms, and in addition because of the resolution of the spectra, the binding energy difference for these different sources of nitrogen is also not obvious. The sulfur $2 \mathrm{p}$ peak from the TOS counter ions is observed at $168 \mathrm{eV}$, which is consistent with the S(IV) oxidation state. We noticed that as a well-known mixed-valence complex, XPS studies on the Creutz-Taube ions had been done a few times previously [70]; we found here that our observations on the peak positions of the binding energy agree well with the reported literature results.

From XPS measurement we can also obtain atomic concentrations of each element $\boldsymbol{C}_{\boldsymbol{i}}$ in the molecules using eq 1 , where $\boldsymbol{A}_{\boldsymbol{i}}$ is the peak area of element $\boldsymbol{i}$ and $\boldsymbol{S}_{\boldsymbol{i}}$ is the sensitivity factor of element $\boldsymbol{i}$.

$$
C_{i}=\frac{A_{i} / S_{i}}{\sum_{i}\left(A_{i} / S_{i}\right)} \times 100
$$

Table 1 lists the peak positions of the binding energy and atomic concentrations for $\mathrm{N}, \mathrm{Ru}$ and $\mathrm{S}$ obtained from this powder sample. We can see that the observed $\mathrm{N}$ to $\mathrm{Ru}$ ratio is $6.12 \pm 0.17$, which is in good agreement with the theoretical ratio of 6:1 for this complex. For the ratio of $\mathrm{S}$ to $\mathrm{Ru}$, the observed value of $2.71 \pm 0.19$ is also close to the theoretical expectation of 2.5 .

Table 1. Binding energy and the relative concentrations of $R u, N$ and $S$ in the CreutzTaube ion powder sample with toluenesulfonate (TOS) as the counter ions.

\begin{tabular}{|c|c|c|c|}
\cline { 2 - 4 } \multicolumn{1}{c|}{} & Ru 3p & N 1s & S 2p \\
\hline $\begin{array}{c}\text { Binding Energy } \\
\text { (eV) }\end{array}$ & $\begin{array}{c}461.8\left(3 \mathrm{p}^{3 / 2}\right) \\
484.7\left(3 \mathrm{p}^{1 / 2}\right)\end{array}$ & 399.7 & 167.9 \\
\hline Rel. Conc. (\%) & 10.2 & 62.3 & 27.5 \\
\hline
\end{tabular}

\subsection{Selective Binding Properties on Surfaces}

The selective binding properties of the Creutz-Taube ion were investigated on several hydrophilic and hydrophobic substrates. The first hydrophilic substrates we tested were silicon [100] wafers covered with a layer of freshly grown native oxide of about $10 \AA$ thickness; and the same types of silicon wafers but covered with a complete OTS monolayer were used as the hydrophobic substrates. After the substrates were immersed in $5 \mathrm{mM}$ aqueous solutions of the Creutz-Taube ions for three hours, they were taken out from the solution and then rinsed with running water for at least $5 \mathrm{~min}$ before finally drying in a stream of nitrogen. Figure 3 shows the obtained XPS results for both the 
hydrophilic silicon native oxide substrate (top lines) and the hydrophobic OTS covered silicon substrate (bottom lines) after exposure to the Creutz-Taube ions. High resolution scans were performed to determine the binding energies and atomic concentrations of $\mathrm{Ru}$ and $\mathrm{N}$. From this figure, we see that only on the hydrophilic $\mathrm{SiO}_{2}$ surface where both $\mathrm{Ru}$ and $\mathrm{N}$ were observed. In contrast, neither of them was detected on the OTS-covered $\mathrm{SiO}_{2}$ substrate.

Figure 3. XPS spectra of a $\mathrm{SiO}_{2}$ substrate (top curves) and an OTS covered $\mathrm{SiO}_{2}$ substrate (bottom curves) after soaking in an aqueous solution of Creutz-Taube ions. Shown in (A), (B), (C), and (D) are the XPS regions corresponding to element components Ru 3p, N 1s, $\mathrm{Ru} 3 \mathrm{~d}$ and $\mathrm{S} \mathrm{2s}$, respectively. All peaks were fitted with Gauss-Lorentz peaks to obtain peak area information. A linear base line was used in the peak fitting processes.
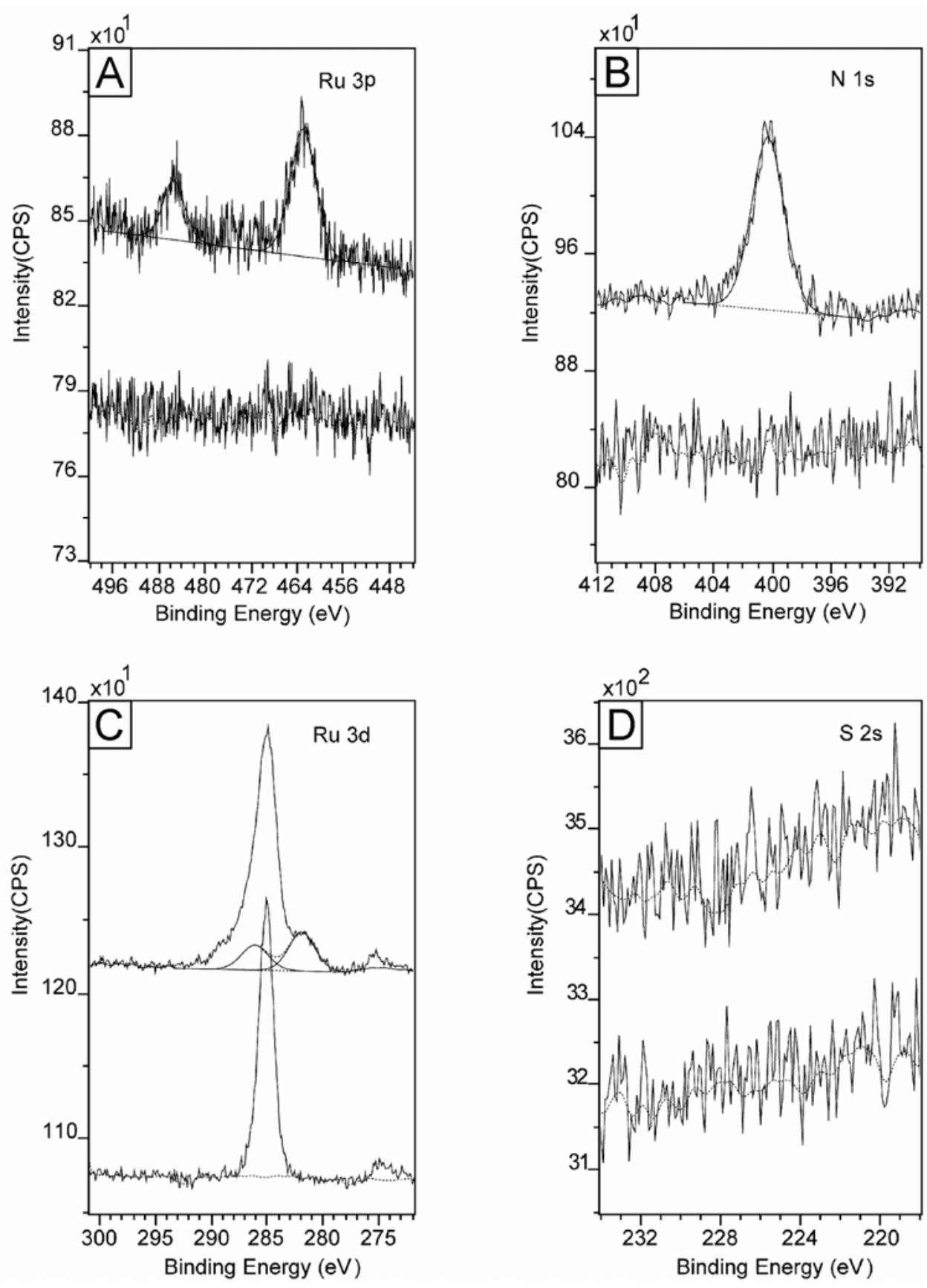
For convenience, here the Si $2 p$ peak $(99.3 \mathrm{eV})$ was used to calibrate the binding energy shift caused by surface charging effects. Due to the different calibration methods used here and in the powder sample (Figure 2), the $\mathrm{C} 1 \mathrm{~s}$ peak of the adventitious carbon now appears at $285.4 \mathrm{eV}$, which is upshifted about $1 \mathrm{eV}$. When this factor is taken into account, after the Creutz-Taube ion attached to $\mathrm{SiO}_{2}$ substrate, the binding energy of $\mathrm{Ru}(485.7 \mathrm{eV}, 462.4 \mathrm{eV}$ for $3 \mathrm{p}$ and $281.5 \mathrm{eV}$ for $3 \mathrm{~d}$ ) and $\mathrm{N}$ $(400.0 \mathrm{eV}, 1 \mathrm{~s})$ peaks are close to those obtained for the powder sample, implying that the molecules did not undergo obvious chemical changes after binding to the $\mathrm{SiO}_{2}$ surface. Based on the peak area, the observed ratio of $\mathrm{N}(1 \mathrm{~s})$ to $\mathrm{Ru}(3 \mathrm{p})$ is about 5.92, which is consistent with the expected ratio of 6:1 if $\left(\mathrm{NH}_{3}\right)_{5} \mathrm{Ru}-\mathrm{pz}-\mathrm{Ru}\left(\mathrm{NH}_{3}\right)_{5}$ core of the molecule remains intact after attaching to the surface. For the operation of QCA, it is crucial to keep the intervalence-charge-transfer property of the Creutz-Taube ion on surfaces. If the molecules break on the surface, this charge-transfer process between the two Ru atoms would not be possible. The counter ions of the molecules were also investigated and the result is shown in Figure 3D. Because of the existence of a plasma band for $\mathrm{SiO}_{2}$ at a region that can overlap with the S(IV) $2 p$ peak, S 2 s was measured instead to check the binding of the counter ions on the substrate. Here we see no signal of sulfur, indicating no binding of TOS.

Figure 4. XPS spectra of a $\mathrm{SiO}_{2}$ substrate (top curve) and an OTS covered $\mathrm{SiO}_{2}$ substrate (bottom curve) after soaking in an aqueous solution of Creutz-Taube ions. The XPS spectrum of a powder sample of Creutz-Taube ions, with $\left(\mathrm{PF}_{6}\right)^{-}$as the counter ions, is also shown in the figure (middle curve).

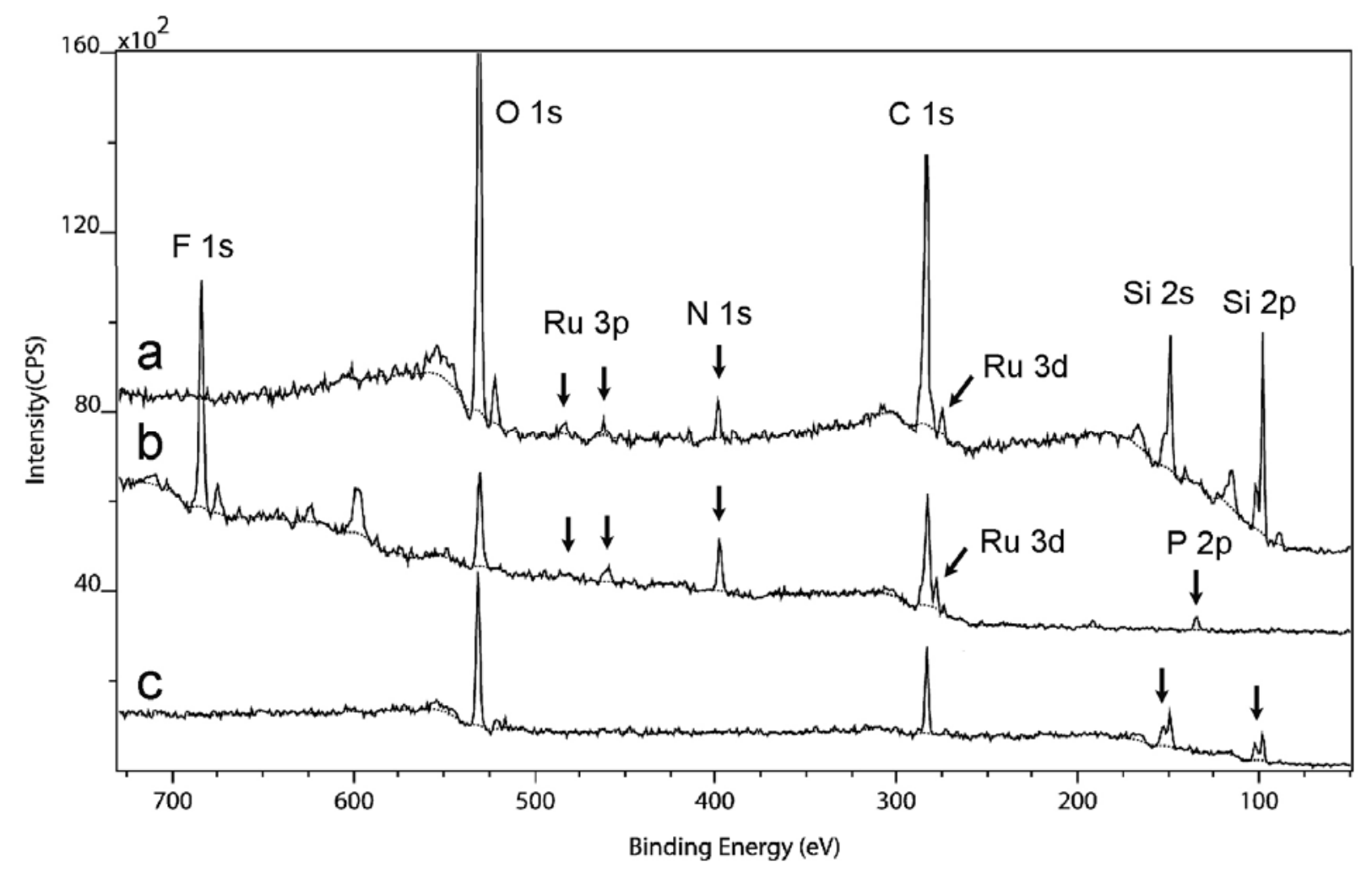

In order to find out whether the lack of anion binding is true for other counter ions, the CreutzTaube ions with a different counter ion - $\left(\mathrm{PF}_{6}\right)^{-}$- was prepared and used to study its selective binding on the same $\mathrm{SiO}_{2}$ and OTS-covered $\mathrm{SiO}_{2}$ substrates. The result is shown in Figure 4. Here XPS spectra 
obtained from survey scans are used and compared. The result of the XPS measurement on a corresponding powder sample was also shown in the middle of this figure. The $F$ 1s peak corresponding to the $\left(\mathrm{PF}_{6}\right)^{-}$anion in the powder sample is indicated in this figure. Here we see again the appearance of both $\mathrm{Ru}$ and $\mathrm{N}$ on the $\mathrm{SiO}_{2}$ surface but not on the OTS covered $\mathrm{SiO}_{2}$ surface. For both $\mathrm{SiO}_{2}$ surface and the OTS-covered $\mathrm{SiO}_{2}$ surface, both the $\mathrm{F} 1 \mathrm{~s}$ peak and the $\mathrm{P} 2 \mathrm{p}$ peak observed in the powder spectra were not observed even though F 1s has a very high sensitivity factor for XPS detection [74]. So from both of these two tests, we can conclude that the Creutz-Taube ions only bound to the $\mathrm{SiO}_{2}$ substrate, but not to the OTS-covered $\mathrm{SiO}_{2}$ substrate. The two counter ions $-\mathrm{TOS}$ and $\mathrm{PF}_{6}$ as used in this study, showed no binding on either the hydrophilic or the hydrophobic surfaces.

Another type of surfaces used in the selective binding study were hydrophilic organic SAMs (i.e., HUT) or hydrophobic organic SAMs (i.e., ODT) on gold. The surface attachment samples were prepared the same way as those used in the $\mathrm{SiO}_{2}$ and $\mathrm{OTS} / \mathrm{SiO}_{2}$ binding tests. Figure 5 gives the corresponding XPS results of the binding property on these two substrates. The Au $4 \mathrm{f}$ peak at $84 \mathrm{eV}$ was used to calibrate the peak positions of all other elements. From this figure, both $\mathrm{Ru}$ (e.g., $\mathrm{Ru} 3 \mathrm{p}$ at $484.9 \mathrm{eV}$ and $462.4 \mathrm{eV})$ and $\mathrm{N}(1 \mathrm{~s}, 399.8 \mathrm{eV})$ are seen on the HUT covered gold substrate, but not on the ODT covered gold substrate, which indicated no binding of the Creutz-Taube ion on this hydrophobic surface. For the HUT covered gold substrate, the binding energy of both Ru and N peaks were similar to the same elemental peaks of the Creutz-Taube ions on $\mathrm{SiO}_{2}$ substrate. The intensity, however, appears weaker than that on $\mathrm{SiO}_{2}$ as manifested by the signal/noise ratio shown in this figure. The ratio of the atomic concentration of $\mathrm{N}$ to $\mathrm{Ru}(5.74: 1)$ remains close to the value obtained for the powder sample indicating the molecules still appeared to be intact. Since the SAMs has the S-Au bond on the gold substrate, both substrates were expected to observe S peaks on their surfaces. Here peaks centered around $162 \mathrm{eV}$ were assigned to S $2 \mathrm{p}$ in the thiol groups [74]. For the HUT covered gold substrate, we also observed an additional $\mathrm{S} 2 \mathrm{p}$ peak with binding energy around $168 \mathrm{eV}$. By comparing to the $S 2 p$ peak from the powder sample (Figure 2D), we can assign this additional peak to the $S$ in the TOS anion. So for the second set of hydrophilic and hydrophobic substrates, the Creutz-Taube ion also selectively bound only on the hydrophilic surfaces, but not on the hydrophobic surface. Different from the binding on the hydrophilic $\mathrm{SiO}_{2}$ substrate, here both cations and anions were observed on the HUT covered gold substrate.

Since for the implementation of QCA, all candidate molecules will have to be patterned into arrayed structures on a surface in order to carry out logical computing, for the purpose of surface patterning, the selective binding property of the Creutz-Taube ions on PMMA, a widely-used hydrophobic type electron beam resist, was also investigated and compared with that on $\mathrm{SiO}_{2}$. In addition, in order to investigate the selective binding property of the Creutz-Taube ions at a micrometer scale, a partially $\mathrm{PMMA}$-covered $\mathrm{SiO}_{2}$ substrate with twelve $150 \times 150 \mu \mathrm{m}^{2}$ open $\mathrm{SiO}_{2}$ squares with $50 \mu \mathrm{m}$ spacing between each square (Figure 6) was also prepared by electron beam lithography. Figure 7 shows the obtained XPS result for a fully PMMA-covered $\mathrm{SiO}_{2}$ substrate (bottom), a bare $\mathrm{SiO}_{2}$ substrate (top) and a micropatterned $\mathrm{SiO}_{2}$ substrate (middle) after they were soaked in the Creutz-Taube ion water solution and then rinsed. The total absence of $\mathrm{N}$ and $\mathrm{Ru}$ peaks in the bottom lines indicates that the Creutz-Taube ions did not bind to the PMMA surface. For the micropatterned sample, because the XPS system incorporates no mechanism for alignment, the beam was swept until a maximum signal was obtained. 
Figure 5. XPS spectra of a HUT covered gold substrate (top curves) and an ODT covered gold substrate (bottom curves) after soaking in an aqueous solution of Creutz-Taube ions. Shown in (A), (B), (C), and (D) are the XPS regions corresponding to Ru 3p, N 1s, Ru 3d and $S 2 p$, respectively.
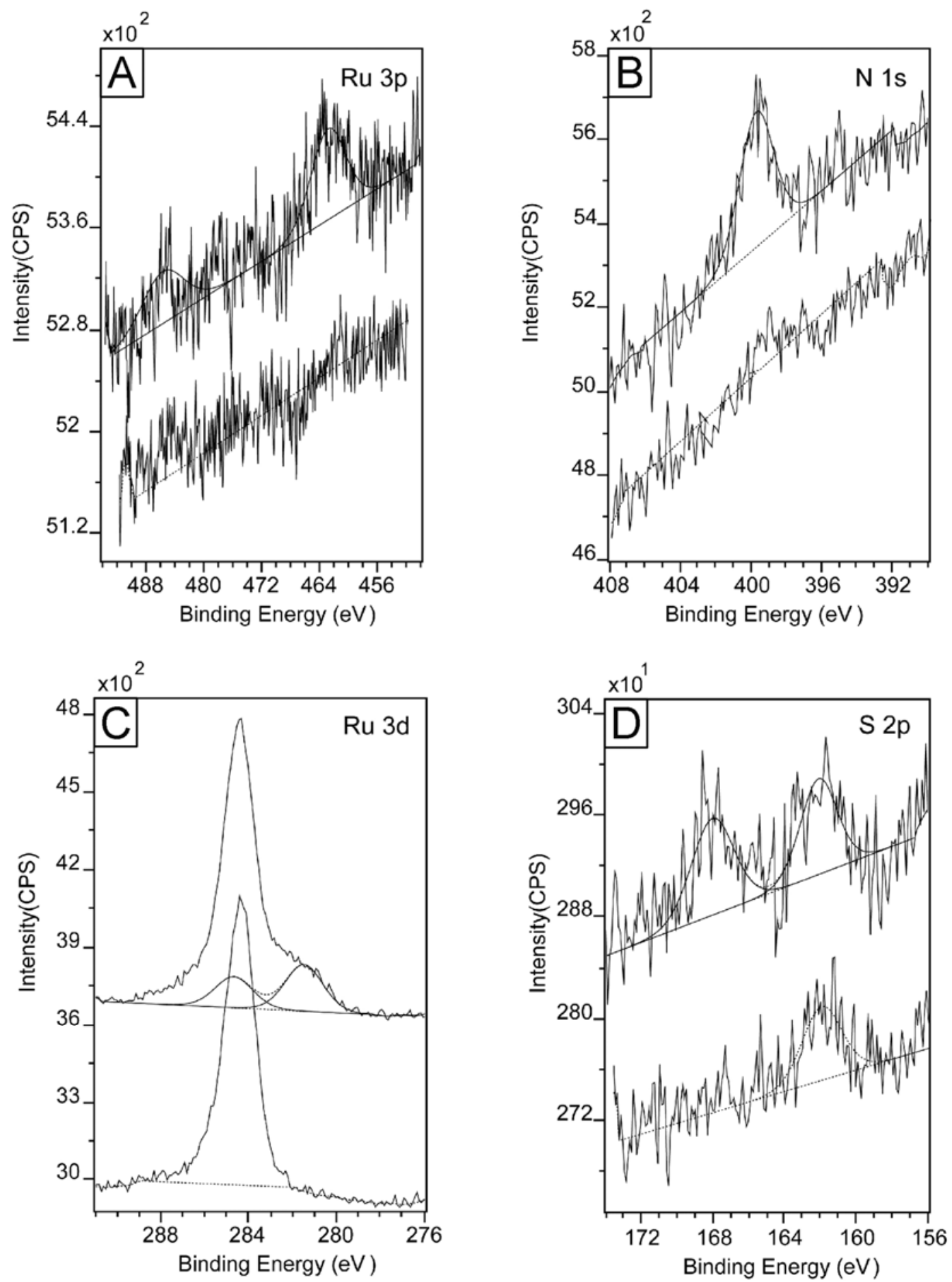

In such a measurement, about ten percent of the area exposed by the XPS beam contained the squares (XPS beam size $\sim 3 \mathrm{~mm}^{2}$, total area of open $\mathrm{SiO}_{2} \sim 0.27 \mathrm{~mm}^{2}$ ). From Figure 7, we see the peak intensities of $\mathrm{Ru} 3 \mathrm{p}$ and $\mathrm{N} 1 \mathrm{~s}$ are reasonably large for the area exposed when compared to the $\mathrm{SiO}_{2}$ sample (intensities ratio $\sim 1: 10$ ). The measured $\mathrm{N}: \mathrm{Ru}$ ratio of 5.67 indicates that the Creutz-Taube ion selectively bound to the oxide squares formed by EBL in much the same way as they bound to the 
large area bare $\mathrm{SiO}_{2}$ substrate. Sulfur $2 \mathrm{~s}$ region was scanned to determine the binding of TOS anions on the PMMA fully- or partially-covered substrates. From Figure 7C, we see none of the substrates showed any sulfur peak, indicating no binding of the TOS on PMMA surface.

Figure 6. Schematic illustration of the partially exposed $\mathrm{SiO}_{2}$ substrate covered by PMMA. The white areas are the twelve $150 \times 150 \mu \mathrm{m}$ open $\mathrm{SiO}_{2}$ squares.

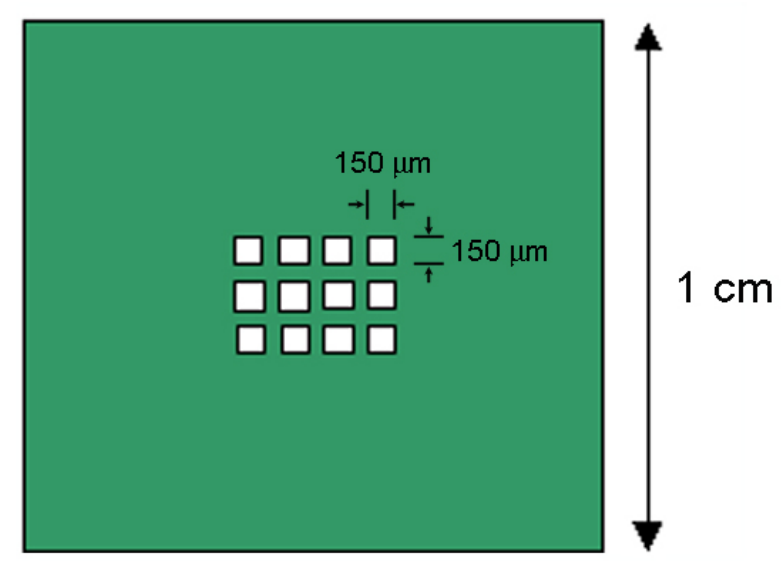

Figure 7. Comparison of the binding of the Creutz-taube ions on three different substrates: a $\mathrm{SiO}_{2}$ substrate (top curve), a partially exposed $\mathrm{SiO}_{2}$ substrate covered by PMMA (middle curve) and a PMMA fully covered $\mathrm{SiO}_{2}$ substrate (bottom curve). Shown in (A), (B) and (C) are the XPS regions corresponding to element components $\mathrm{N} 1 \mathrm{~s}, \mathrm{Ru} 3 \mathrm{p}$ and $\mathrm{S} 2 \mathrm{~s}$, respectively.
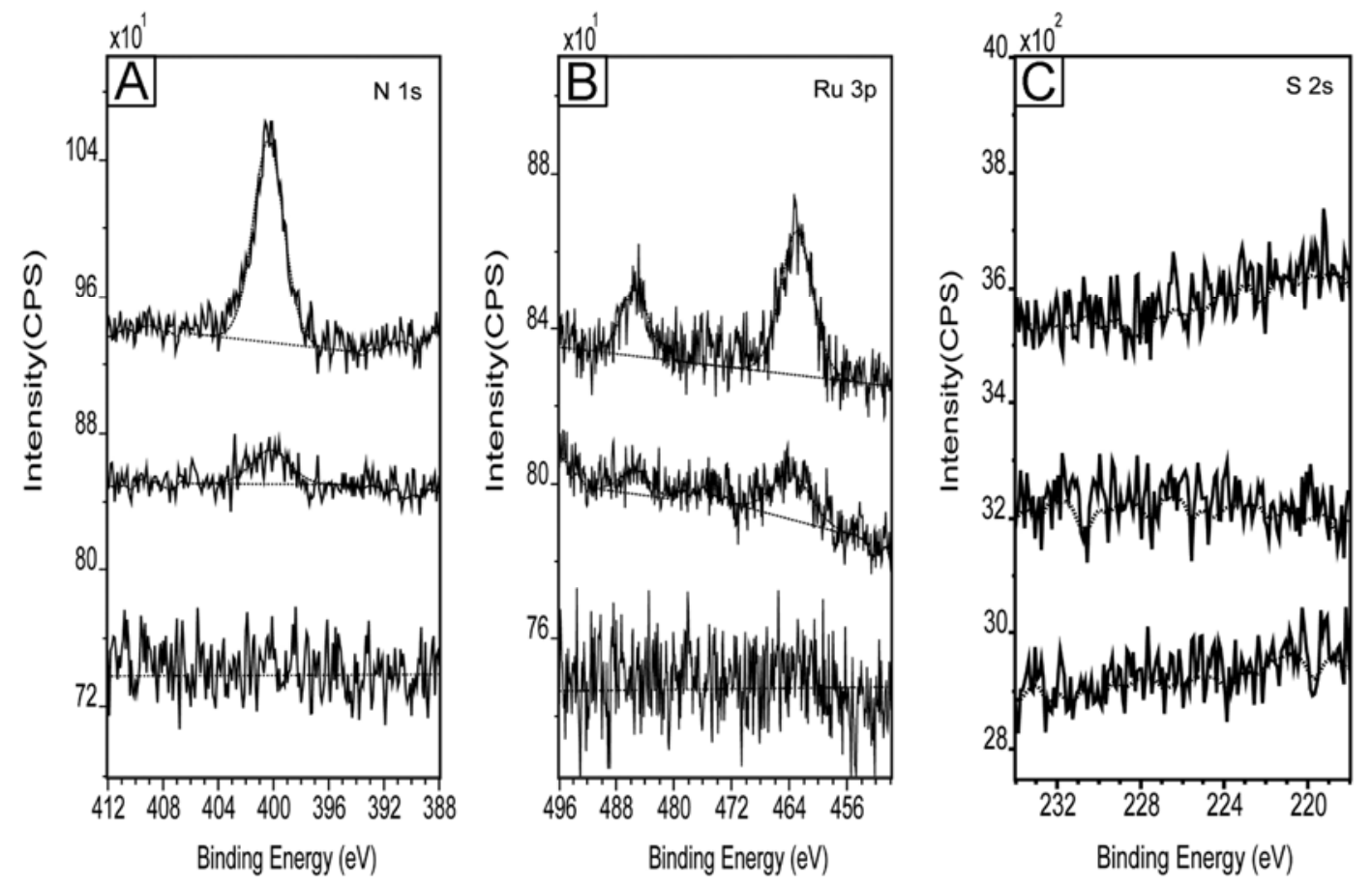

As a summary, Table 2 below lists all the XPS peak positions, relative atomic concentrations and the selective binding properties of the Creutz-Taube ion on the hydrophilic and hydrophobic substrates we tested. 
Table 2. Selective binding properties of the Creutz-Taube ions (CT5) on hydrophilic and hydrophobic substrates.

\begin{tabular}{|c|c|c|c|c|c|c|}
\hline & \multirow{4}{*}{$\begin{array}{c}\mathbf{R u} \\
462.4\left(3 \mathrm{p}^{3 / 2}\right) \\
485.7\left(3 \mathrm{p}^{1 / 2}\right)\end{array}$} & & & & \\
\hline & & & $\mathbf{N}$ & $\mathbf{S}$ & $\mathbf{P}$ & $\mathbf{F}$ \\
\hline \multirow{3}{*}{$\begin{array}{c}\mathrm{CT} 5(\mathrm{TOS})_{5} \text { on } \\
\mathrm{SiO}_{2}\end{array}$} & P F $(\mathrm{eV})$ & & $4000(1 \mathrm{~s})$ & \multirow{3}{*}{ No binding } & \multirow{3}{*}{--} & \multirow{3}{*}{--} \\
\hline & & & & & & \\
\hline & Rel. Conc. (/Ru) & 1 & 5.78 & & & \\
\hline \multirow{2}{*}{$\begin{array}{c}\mathrm{CT} 5(\mathrm{TOS})_{5} \text { on } \\
\mathrm{OTS} / \mathrm{SiO}_{2}\end{array}$} & B. E. $(e V)$ & \multirow{2}{*}{ No binding } & \multirow{2}{*}{ No binding } & \multirow{2}{*}{ No Binding } & \multirow{2}{*}{--} & \multirow{2}{*}{--} \\
\hline & Rel. Conc. (/Ru) & & & & & \\
\hline \multirow{2}{*}{$\begin{array}{c}\text { CT5(TOS })_{5} \text { on } \\
{\text { PMMA } / \mathrm{SiO}_{2}}\end{array}$} & B. E. $(\mathrm{eV})$ & \multirow{2}{*}{ No binding } & \multirow{2}{*}{ No binding } & \multirow{2}{*}{ No Binding } & \multirow{2}{*}{--} & \multirow{2}{*}{--} \\
\hline & Rel. Conc. (/Ru) & & & & & \\
\hline \multirow{2}{*}{$\begin{array}{c}\text { CT5(TOS) })_{5} \text { on } \\
\text { HUT/Au }\end{array}$} & B. E. $(\mathrm{eV})$ & $\begin{array}{l}462.4\left(3 p^{3 / 2}\right) \\
484.9\left(3 p^{1 / 2}\right)\end{array}$ & $399.8(1 \mathrm{~s})$ & $\begin{array}{l}168.1 \text { (2p TOS }) \\
162.0(2 \mathrm{p} \text { Thiol })\end{array}$ & \multirow{2}{*}{--} & \multirow{2}{*}{--} \\
\hline & Rel. Conc. (/Ru) & 1 & 5.41 & $\begin{array}{l}1.70(2 \mathrm{p} \text { TOS }) \\
1.66(2 \mathrm{p} \text { Thiol })\end{array}$ & & \\
\hline \multirow{2}{*}{$\begin{array}{c}\text { CT5(TOS) })_{5} \text { on } \\
\text { ODT/Au }\end{array}$} & B. E. $(\mathrm{eV})$ & \multirow{2}{*}{ No binding } & \multirow{2}{*}{ No binding } & \multirow{2}{*}{ No binding } & \multirow{2}{*}{--} & \multirow{2}{*}{--} \\
\hline & Rel. Conc. (/Ru) & & & & & \\
\hline \multirow{2}{*}{$\begin{array}{c}\text { CT5 }\left(\mathrm{PF}_{6}\right)_{5} \\
\text { Powder }\end{array}$} & B. E. $(\mathrm{eV})$ & $\begin{array}{l}462.7\left(3 p^{3 / 2}\right) \\
484.5\left(3 p^{1 / 2}\right)\end{array}$ & 399.7 (1s) & \multirow{2}{*}{--} & $135.9(2 p)$ & $686.5(1 \mathrm{~s})$ \\
\hline & Rel. Conc. (/Ru) & 1 & 6.08 & & 2.42 & 14.8 \\
\hline \multirow{2}{*}{$\begin{array}{c}\mathrm{CT} 5\left(\mathrm{PF}_{6}\right)_{5} \text { on } \\
\mathrm{SiO}_{2}\end{array}$} & B. E. $(\mathrm{eV})$ & $\begin{array}{l}461.5\left(3 p^{3 / 2}\right) \\
484.5\left(3 p^{1 / 2}\right)\end{array}$ & $399.8(1 \mathrm{~s})$ & \multirow{2}{*}{--} & \multirow{2}{*}{$\begin{array}{c}\text { No } \\
\text { binding }\end{array}$} & \multirow{2}{*}{$\begin{array}{c}\text { Bo } \\
\text { binding }\end{array}$} \\
\hline & Rel. Conc. (/Ru) & 1 & 6.40 & & & \\
\hline
\end{tabular}

From the above experiments, it is clear that the Creutz-Taube ion only binds on hydrophilic surfaces, but not on hydrophobic ones. We believe it is the attractive or repulsive interaction between the Creutz-Taube ions and the surface that lead to such selective binding properties. The isoelectric point of $\mathrm{SiO}_{2}$ surface is around 3.8 [68], so at any $\mathrm{pH}$ larger than 3.8, the surface of $\mathrm{SiO}_{2}$ carries a significant amount of negative charges. Since the Creutz-Taube molecules are highly charged cations, and the $\mathrm{pH}$ of the solution is neutral, the strong electrostatic attraction between the cations and the anionic surface will make them bind together [48]. For the same reason, since the counter ions and the surface are both anionic, due to Coulombic repulsion, the binding of the anions, such as $\mathrm{PF}_{6}$ or TOS, on $\mathrm{SiO}_{2}$ surface is not favorable when compared to the cations binding. It is very likely that the anions will be removed during any solvent rinsing processes. 
For the $-\mathrm{OH}$ terminated $\mathrm{SAMs}$ grown on gold, the surface charge will be smaller than for $\mathrm{SiO}_{2}$. Because of their high pKa values ( $>10)$, the $-\mathrm{OH}$ groups are not easy to dissociate. Despite the lack of a large negative surface charge, hydrogen bonds can likely still be formed between the $\mathrm{H}$ atoms existing in the $\mathrm{NH}_{3}$ groups of the cations and the oxygen atoms in the $\mathrm{OH}$ groups on the surface. The XPS signal of Ru and $\mathrm{N}$ from the Creutz-Taube ions on to the HUT surface is weaker than the signals on the $\mathrm{SiO}_{2}$. This is most likely due to the fact that such hydrogen bonding is less strong than the electrostatic interaction between the highly charged cations and the anionic $\mathrm{SiO}_{2}$ surface. Since there is no repulsive force between these $\mathrm{OH}$ groups on the SAMs and the negatively charged counter ions, it is possible to form hydrogen bonds between the $\mathrm{O}$ atoms in TOS and the $\mathrm{OH}$ group from the SAM layer. Indeed, the HUT surface is the only one that the counter ions bind.

For hydrophobic surfaces, such as the long chain $\mathrm{CH}_{3}$ terminated $\mathrm{SAMs}$ on $\mathrm{SiO}_{2}$ or gold, the only possible interaction between the Creutz-Taube ion and these $\mathrm{CH}_{3}$ functional groups is the Van der Waals force, which is much weaker, compared to hydrogen bonds and electrostatic interactions. During solvent rinsing, both cations and anions could be easily removed from the hydrophobic surfaces.

\subsection{Inorganic SAMs: Characterization of the Creutz-Taube Ion on $\mathrm{SiO}_{2}$}

At this point, we know that the Creutz-Taube ions only bind to hydrophilic surfaces, but how they bind to the surface after their attachment, such as the molecular orientations and whether they form monolayer or multilayers on the surfaces, is still unknown. In order to find out the answers to these questions, time-dependent XPS, ellipsometry, and AFM surface roughness analysis and line section analysis were carried out to acquire more details on the attachment of the Creutz-Taube ions on surfaces. For the interests of QCA realization, the following discussion was focused on understanding the binding of the Creutz-Taube ions on $\mathrm{SiO}_{2}$ substrate.

When a $\mathrm{SiO}_{2}$ substrate is soaked in the Creutz-Taube ion solution, the Creutz-Taube ion in the solution will begin to attach to the adsorption sites on $\mathrm{SiO}_{2}$. With increased soaking time, more and more Creutz-Taube ions are expected to attach to the $\mathrm{SiO}_{2}$ surface, so the surface coverage or the $\mathrm{Ru}$ to Si ratio in the XPS measurement will keep increasing with the increasing sample soaking time in solution. If the attachment of the Creutz-Taube ion on $\mathrm{SiO}_{2}$ surface is due to the strong electrostatic interaction between these highly charged cations and the deprotonated surface $-\mathrm{OH}$ groups, once all the available binding sites are occupied, the attachment of the Creutz-Taube ion on $\mathrm{SiO}_{2}$ surface should stop. It is possible that the Creutz-Taube ion will keep adsorbing onto the already formed the Creutz-Taube ion layer, but the interaction between these species will be very weak when compared to the strong interaction between the first layer of the Creutz-Taube ion and the negatively charged surface. During the rinsing of the sample, these weakly bound Creutz-Taube ion should be easily removed. So it is expected that for the binding of the Creutz-Taube ion on $\mathrm{SiO}_{2}$ surface, there should be a self-limiting process to form a monolayer of the Creutz-Taube ion on the $\mathrm{SiO}_{2}$ surface, so the $\mathrm{Ru}$ to $\mathrm{Si}$ ratio would reach a constant value after a certain time of soaking the $\mathrm{SiO}_{2}$ substrate in the CreutzTaube ion solution.

XPS samples with different soaking time ranging from 5 min to 1 week in the Creutz-Taube ion solution were used. The atomic concentration of the $\mathrm{Ru} 3 \mathrm{p}$ at $462 \mathrm{eV}$ and $484 \mathrm{eV}$ and the total 
concentration of the Si $2 p$ at $99.3 \mathrm{eV}(0)$ and $103.3 \mathrm{eV}$ (IV) were compared for all the samples. Figure 8 shows the results. Saturation coverage was achieved after about 30 min soaking time. The $\mathrm{Ru}$ to $\mathrm{Si}$ ratio reached a constant value around 0.02 . The corresponding $\mathrm{N} / \mathrm{Si}$ ratio was also calculated and it gave a value around 0.11 . The observation of a saturation coverage indicates a self-limiting adsorption process of the Creutz-Taube ion on $\mathrm{SiO}_{2}$ surface. This result is crucial for the fabrication of QCA devices on surface. A multilayer formation of the Creutz-Taube ion would make the separation of these cells difficult and thus almost impossible to pattern them into arrayed single layer structures. Also shown in Figure 8 is the corresponding N/Ru ratio for these samples prepared with different soaking time. Here almost constant values were observed, and the averaged ratio is $5.94 \pm 0.59$, which is very close to the expected theoretical value of 6 . This result further suggested that the Creutz-Taube ions did not undergo dissociation and remain intact on the $\mathrm{SiO}_{2}$ surface regardless how long the substrate were soaked.

Figure 8. Time-dependent XPS results of the attachment of the Creutz-Taube ions on $\mathrm{SiO}_{2}$ substrate. The $\mathrm{N} / \mathrm{Ru}$ and $\mathrm{Ru} / \mathrm{Si}$ ratios were plotted against the soaking time of the sample substrates.

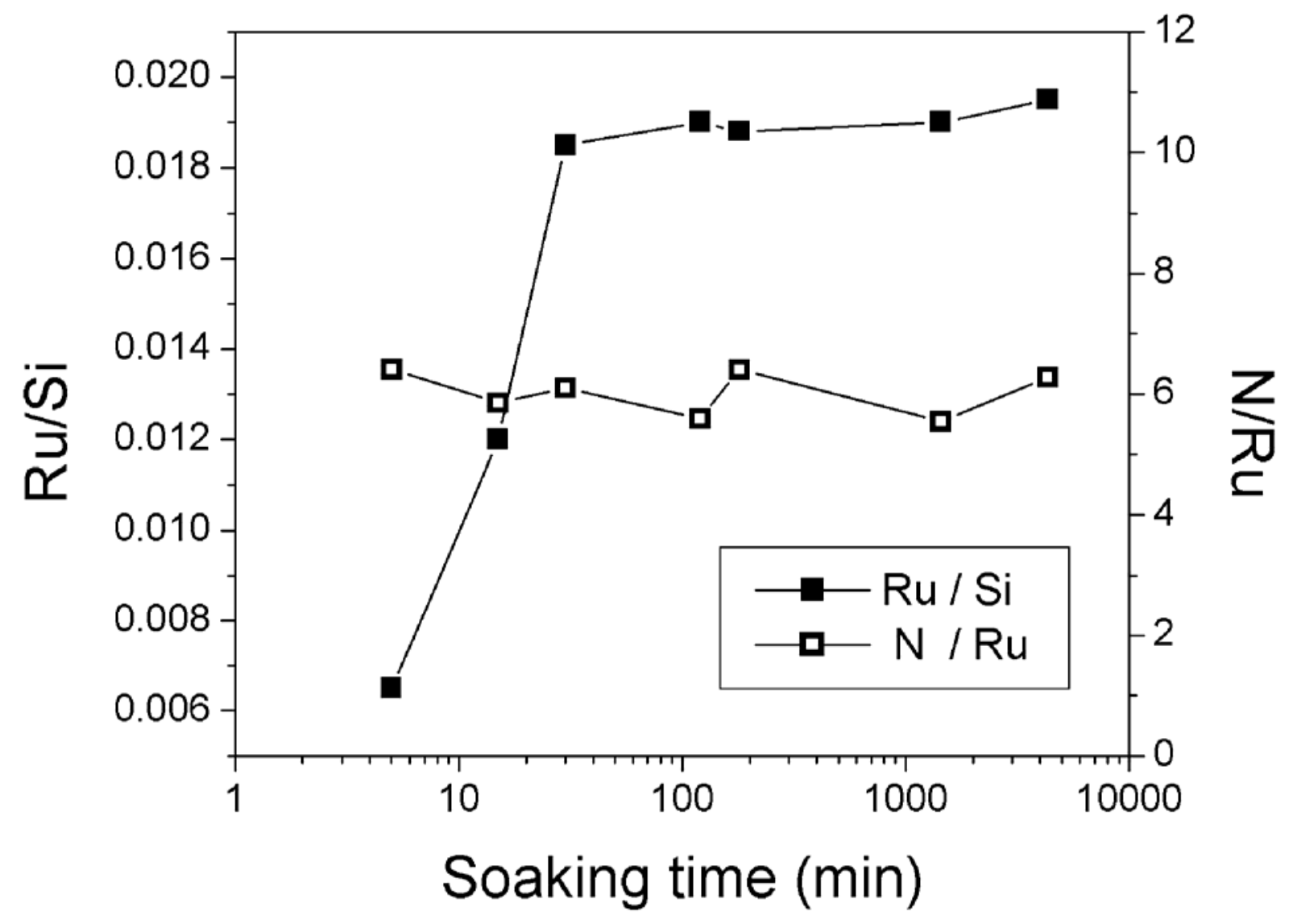

Though we know the surface density of the $\mathrm{Si}-\mathrm{OH}$ group is about 4.6 per $\mathrm{nm}^{2}$ on $\mathrm{SiO}_{2}$, the surface coverage of the Creutz-Taube ions on $\mathrm{SiO}_{2}$ can not be obtained directly from the $\mathrm{Ru}$ to $\mathrm{O}$ or $\mathrm{Ru}$ to $\mathrm{Si}$ ratio [62]. The reason is that the ratio between $\mathrm{Ru}$ and $\mathrm{O}$ or Si does not relate only to the surface $\mathrm{Si}-\mathrm{OH}$ group, the intensity of $\mathrm{O}$ or Si XPS peaks always has contributions from the silicon oxide underneath the surface layer considering the typical XPS penetration depth is larger than $50 \AA$. So the value of Ru 
to $\mathrm{Si}(0.02)$ or $\mathrm{N}$ to $\mathrm{Si}(0.11)$ ratios could not get the surface area occupied by each of the Creutz-Taube ion, however, by comparing this ratio to other molecules with known coverage (area per molecule) and $\mathrm{N}$ to $\mathrm{Si}$ value in similar condition, we can obtain this information indirectly. The following shows how we used APTES $\left(\mathrm{NH}_{2}-\left(\mathrm{CH}_{2}\right)_{3}-\mathrm{Si}-\left(\mathrm{OC}_{2} \mathrm{H}_{5}\right)_{3}\right)$ to calculate the coverage for the Creutz-Taube ion on native silicon oxide.

It has been known that for fully covered self-assembled organic monolayers, the area occupied by each molecule is around $22 \AA^{2}[17-19,68]$. APTES which contains one $\mathrm{NH}_{2}$ group per molecule, so if we use the same silicon substrate as used in the Creutz-Taube ion surface attachment studies to form APTES SAMs, by comparing the N/Si ratio for these two molecules, we can calculate out the surface coverage for the Creutz-Taube ions on silica using Eq. 2:

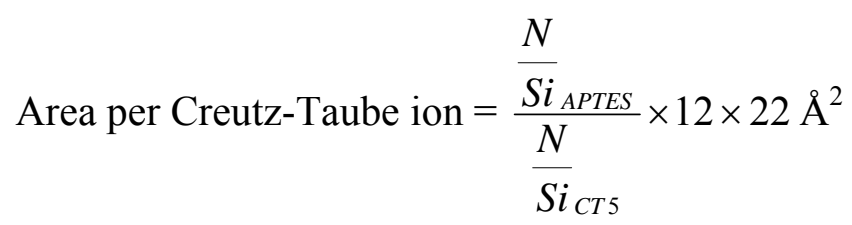

The factor of 12 is due to the fact that each of the Creutz-Taube ion contains 12 nitrogen atoms. The APTES SAMs on native silicon oxide were prepared in a similar way as OTS SAMs on native silicon oxide [69]. Monolayer formation was confirmed by ellipsometric measurement where a thickness of $\sim 6-7 \AA$ (theoretical value based on CHEM 3D model $\sim 6 \AA$ ) was obtained. Figure 9 shows the XPS results for APTES on the same type of $\mathrm{SiO}_{2}$ substrate, here the ratio of $\mathrm{N}$ to $\mathrm{Si}$ (both $\mathrm{IV}$ and 0 ) is 0.0525 for the APTES SAMs. Considering the saturated $N$ to Si ratio (0.11) for the Creutz-Taube ion on silica surface, the calculated area per cation on surface is $\sim 120 \AA^{2}$. For fully covered Creutz-Taube ion monolayer, this value is close to the theoretical value of $85 \AA^{2}$ for the area when the molecule adopts a lying-down orientation. Also because there are about 4.6 negative charges per $\mathrm{nm}^{2}$ on $\mathrm{SiO}_{2}$ surface, for a fully covered Creutz-Taube ion monolayer, each 5+ charged cation would occupy a surface area $\sim 110 \AA^{2}$ to make it neutralized. This coverage result $\left(120 \AA^{2}\right)$ in fact agrees very well with a "lying-down" orientation of the adsorbed Creutz-Taube ions on the $\mathrm{SiO}_{2}$ surface with the charge compensation provided by the surface.

Besides the coverage results obtained from the XPS studies shown above, another possible way to get such orientation information is to measure the height or thickness of the Creutz-Taube ion monolayer. Different orientations of the Creutz-Taube ion on a surface would give a different thickness of the monolayer. So by measuring the height of the Creutz-Taube ion monolayer on surface, we should be able to get the orientation information. Ellipsometry is a useful tool to measure the thickness of surface films over a large area. We used ellipsometry to characterize the surface attachment of the Creutz-Taube ion on $\mathrm{SiO}_{2}$. Table 3 gives the thickness of the native oxide and the Creutz-Taube ion monolayer. The soaking time was kept longer than three hours in order to ensure a fully formed monolayer. 
Figure 9. XPS spectra of a APTES monolayer covered $\mathrm{SiO}_{2}$ substrate. Shown in (A), (B), (C), and (D) are the XPS regions corresponding to element components of N 1s, Si 2s, C 1s and $\mathrm{Si} 2 \mathrm{p}$, respectively.
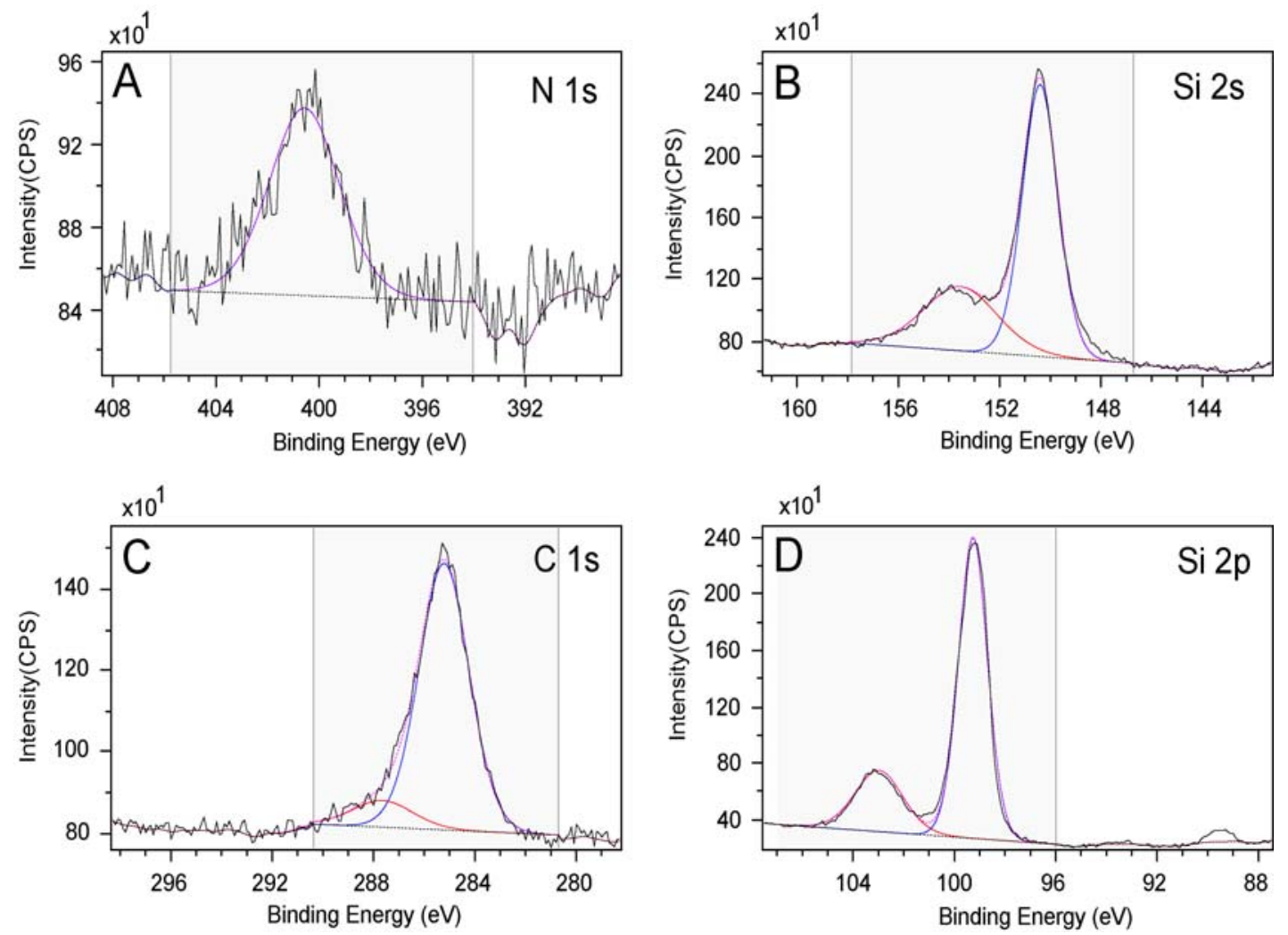

Table 3. Ellipsometric measurement of the Creutz-Taube ion monolayer on $\mathrm{SiO}_{2}$.

\begin{tabular}{|l|c|c|c|c|c|c|c|c|}
\hline $\begin{array}{l}\text { Native } \mathrm{SiO}_{2} \text { thickness } \\
\text { before attachment of CT5 }(\AA)\end{array}$ & 11.3 & 11.8 & 11.4 & 11.3 & 11.6 & 11.4 & 11.6 & $\begin{array}{c}\text { Average } \\
11.5 \pm 0.2\end{array}$ \\
\hline $\begin{array}{l}\text { Total Native } \mathrm{SiO}_{2} \text { and CT5 } \\
\text { thickness after attachment }(\AA)\end{array}$ & 18.0 & 18.6 & 17.6 & 17.9 & 17.8 & 18.1 & 17.6 & $\begin{array}{c}\text { Average } \\
17.9 \pm 0.5\end{array}$ \\
\hline $\begin{array}{l}\text { Calculated CT5 monolayer } \\
\text { thickness }(\AA)\end{array}$ & 6.7 & 6.8 & 6.2 & 6.6 & 6.2 & 6.7 & 6.0 & $\begin{array}{c}\text { Average } \\
6.4 \pm 0.4\end{array}$ \\
\hline
\end{tabular}

The ellipsometric thickness of the final Creutz-Taube ion monolayer is $6.4 \pm 0.4 \AA$. From Figure $10 \mathrm{~A}$, we know that if the Creutz-Taube ion stands up on the surface, we would expect a thickness of $10 \AA$ of the resulting Creutz-Taube ion monolayer, whereas if the lying-down orientation is favored, a thickness of $5 \AA$ would be obtained. Here the value of $6.4 \AA$ indicates the adsorbed Creutz-Taube ion favors a lying-down orientation or at least this orientation dominates on the surface over the standingup orientation if both orientations are mixed on the surface. However, for such mixed orientations, the surface roughness would be higher than the surface roughness when only one orientation were adopted on the surface. 
Figure 10. (A) Schematic structure of the Creutz-Taube ion with its lateral dimension illustrated. (B, C) AFM images of the $\mathrm{SiO}_{2}$ substrate before and after attachment of the Creutz-Taube ions. Increased RMS surface roughness $(0.043 \mathrm{~nm}$ before attachment and $0.158 \mathrm{~nm}$ after attachment) is observed. Line-section analysis lines are also shown on the graphs. (C, D) Line-section analysis results of $(B, C)$.

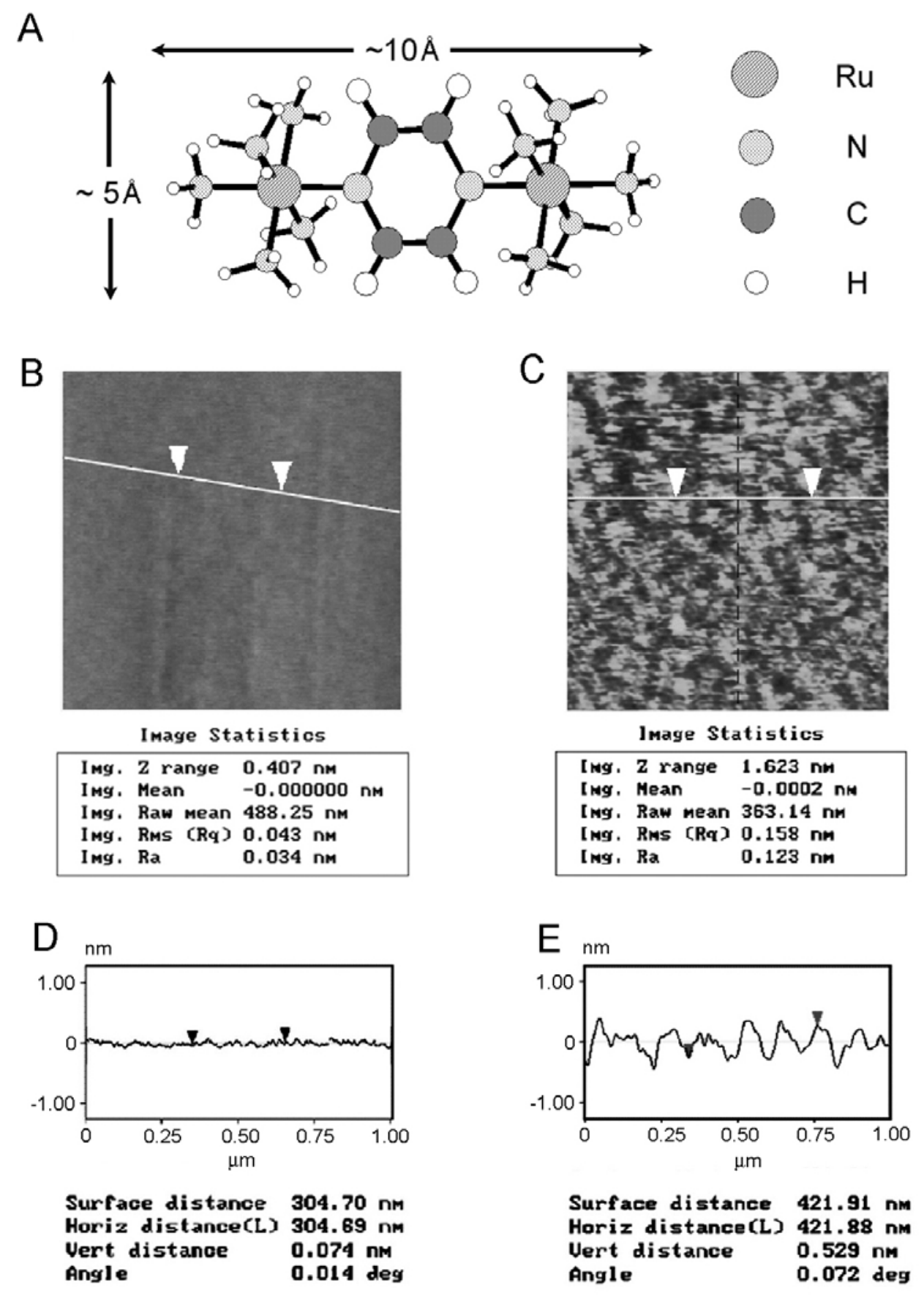

In order to characterize the surface structures of the Creutz-Taube ion on silica at a microscopic level, atomic force microscope (AFM) was used. For line-section analysis, a partially covered CreutzTaube ion film was prepared by soaking the $\mathrm{SiO}_{2}$ substrate in the solution for less than 30 min. Figures $10 \mathrm{~B}$ and $10 \mathrm{C}$ show the corresponding $\mathrm{AFM}$ pictures of the $\mathrm{SiO}_{2}$ substrate before and after the attachment of the Creutz-Taube ions. In Figure 10C, we interpret the bright areas as patches of the 
Creutz-Taube ion covered layer and the dark areas as the uncovered $\mathrm{SiO}_{2}$ substrate. The coverage obtained from the AFM image is around $70 \sim 80 \%$. From Figure 10E, we see the height difference between the Creutz-Taube ion domains and the substrate is about $5.3 \AA$, a value very close to the Creutz-Taube monolayer with a lying-down orientation. The surface roughness obtained on selected bright (the Creutz-Taube ion region) area is about $1.6 \AA$, which suggests a single orientation was adopted for the Creutz-Taube ion when bound to surface (to form a smooth monolayer). A complementary tool to obtain the height information of the covered area is height analysis, a statistical analysis tool from the AFM software that can give the height distributions for the island domains on the substrate. Here we obtained an average value of $0.515 \pm 0.107 \mathrm{~nm}$ for these small islands, which also agrees well with the lying-down orientation of the attached Creutz-Taube ions on surface.

\subsection{Nanolines of the Creutz-Taube Ions Patterned through High-Resolution PMMA Masks}

Because of the high selective binding property of the Creutz-Taube ion on $\mathrm{SiO}_{2}$ and PMMA surface, a procedure of molecular nanopatterning of the Creutz-Taube ion is illustrated in Figure 11A. First a PMMA film is applied to a silicon dioxide layer on a Si substrate, and then an electron beam is used to draw patterns in the PMMA film. After development (to remove the exposed PMMA area in a developer solution), trenches are formed in the PMMA film. The following steps involve soaking the nanopatterned substrate in the Creutz-Taube ion solution and then followed by washing off the PMMA using either acetone or DCM.

Figures $11 \mathrm{~B}$ and $11 \mathrm{C}$ show tapping mode AFM images of two samples prepared by this masking process. In Figure 11B, $200 \mathrm{~nm}$ wide lines (PMMA exposure dose $4.2 \mathrm{nC} / \mathrm{cm}$ ) of the patterned CreutzTaube ions on $\mathrm{SiO}_{2}$ were demonstrated after the PMMA was removed by DCM. Figure 11D gives the average cross sectional profile confined by the box as indicated in Figure 11B. We can see that the height of the $200 \mathrm{~nm}$ wide Creutz-Taube ion lines is about $0.553 \mathrm{~nm}$ away from the edge of the CreutzTaube ion line. Several segments of these two Creutz-Taube ion lines were measured, giving the height of the Creutz-Taube ion lines as from 4 to $6 \AA$. This result further confirms our conclusion on the monolayer formation of the Creutz-Taube ions on $\mathrm{SiO}_{2}$ in that if the Creutz-Taube ion layer is thicker than a monolayer, the height of the $200 \mathrm{~nm}$ wide line could vary considerably when different segments were measured, whereas a monolayer can be only one thickness, as observed here. From Figures $11 \mathrm{~B}$ and $11 \mathrm{D}$ it is clear that the accumulated particles on the edges of the Creutz-Taube ion lines severely affect the measurement results of heights of the Creutz-Taube ion lines. The reason for the aggregation of material at the edges of the lines could be due to the formation of the high edged PMMA debris and is still under investigation. Figure 11C shows another example where a narrow Creutz-Taube ion lines (exposure dose $1.6 \mathrm{nC} / \mathrm{cm}$, line width $35 \mathrm{~nm}$ ) were patterned on $\mathrm{SiO}_{2}$ substrate after removal of the PMMA with DCM. Figure 11E gives the average cross-sectional profiles as shown in Figure 11C, here we found the height of the Creutz-Taube ion line is about $0.9 \mathrm{~nm}$, a value higher than the expected thickness of $0.5 \mathrm{~nm}$ for the formed Creutz-Taube ion monolayer with a lyingdown orientation. The reason for such an observation could be due to the effects of the high edged trenches and the convolution of the AFM tip. Since the width of these lines is around $35 \mathrm{~nm}$, due to the formation of the high edged PMMA debris, the AFM tip (with a70 radius $\sim 15-30 \mathrm{~nm}$ ) may not be able to get deep inside these trenches. So the height from such measurement may appear higher than 
expected. This effect can be eliminated for wider lines of the Creutz-Taube ions (as shown in Figure $11 \mathrm{C})$ on the surface. Given the size of the Creutz-Taube ions $(\sim 5 \times 5 \times 10 \AA)$, it seems that the CreutzTaube ions have been deposited preferentially in the exposed lines, with little or no diffusion to bare $\mathrm{SiO}_{2}$ occurring after removal of the remaining PMMA.

Figure 11. (A) Schematic illustration of the processes for nanopatterning of the CreutzTaube ions on $\mathrm{SiO}_{2}$ substrate. (B, C) Tapping mode AFM images and (D,E) the corresponding line-section analysis of two $200 \mathrm{~nm}$ and $35 \mathrm{~nm}$ lines of the nanopatterened Creutz-Taube ions on $\mathrm{SiO}_{2}$.

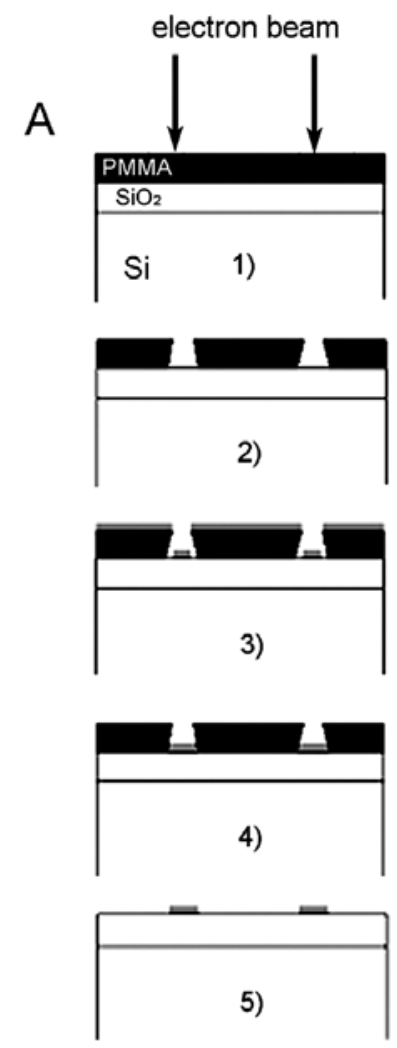

B

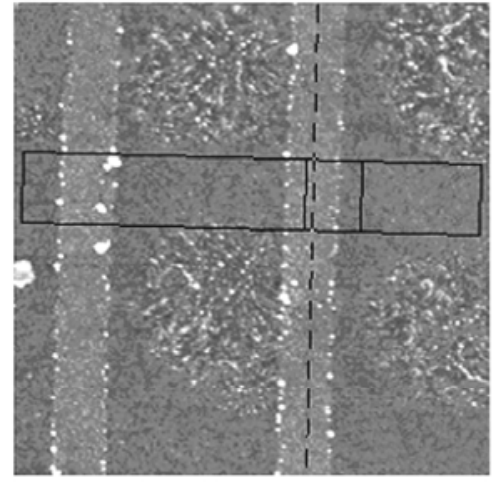

$500 \mathrm{~nm}$

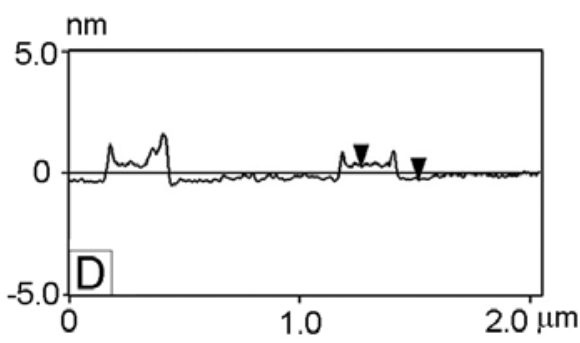

C
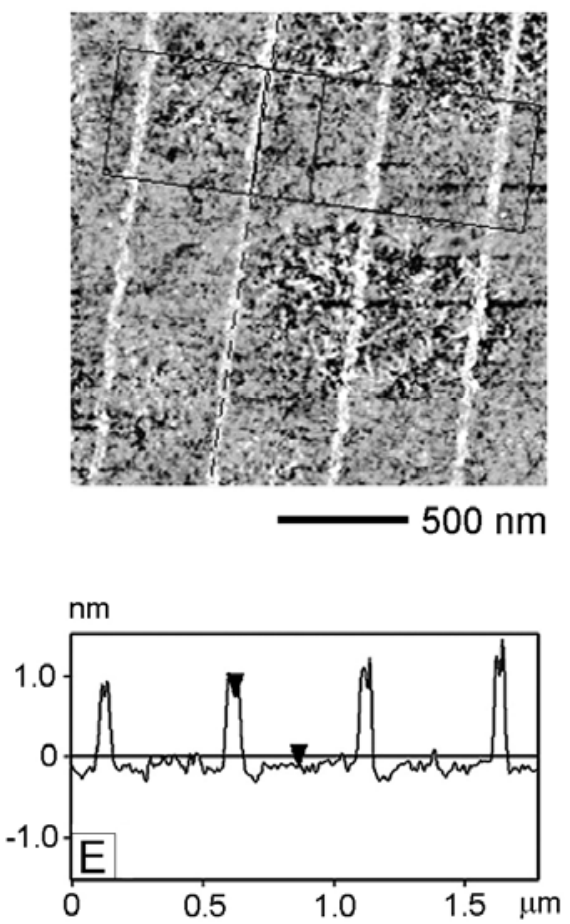

\section{Conclusions}

With the use of XPS, we have found that the Creutz-Taube ion can selectively bind only on hydrophilic types of surfaces, such as $\mathrm{SiO}_{2}$ and $-\mathrm{OH}$ terminated organic SAMs on gold, but not to hydrophobic surfaces, such as $-\mathrm{CH}_{3}$ terminated organic SAMs and poly(methylmethacrylate) (PMMA) thin films. The counter ions of the Creutz-Taube ions do not bind to the anionic $\mathrm{SiO}_{2}$ surfaces or onto any of the non-polar surfaces, although it binds to H-bonding HUT surfaces. Further ellipsometric, atomic force microscopy (AFM) and time-dependent XPS studies suggested that the attached cations could form an inorganic analog of the self-assembled monolayer on $\mathrm{SiO}_{2} \mathrm{substrate}$ with a "lying-down" orientation. The strong electrostatic interaction between the highly charged cations and the anionic $\mathrm{SiO}_{2}$ surface was believed to account for these observations. Based on its selective binding property, patterning of wide $(\sim 200 \mathrm{~nm})$ and narrow $(\sim 35 \mathrm{~nm})$ lines of the Creutz- 
Taube ions on $\mathrm{SiO}_{2}$ surface were demonstrated through PMMA electron resist masks written by electron beam lithography (EBL).

\section{Acknowledgments}

This work was supported under ONR/DARPA grant N00014-01-1-0658. We thank the Notre Dame Radiation Laboratory for use of their AFM.

\section{References and Notes}

1. Somorjai, G.A. Chemistry in Two Dimensions: Surfaces. Cornell University Press: Ithaca, NY, USA, 1981.

2. Porter, M.D.; Bright, T.B.; Allara, D.L.; Chidsey, C.E.D. Spontaneously organized molecular assemblies. 4. Structural characterization of n-alkyl thiol monolayers on gold by optical ellipsometry, infrared spectroscopy, and electrochemistry. J. Am. Chem. Soc. 1987, 109, 3559-3568.

3. Finklea, H.O.; Avery, S.; Lynch, M.; Furtsch, T. Blocking oriented monolayers of alkyl mercaptans on gold electrodes. Langmuir 1987, 3, 409-413.

4. Finklea, H.O.; Robinson, L.R.; Blackburn, A.; Richter, B.; Allara, D.; Bright, T. Formation of an organized monolayer by solution adsorption of octadecyltrichlorosilane on gold: Electrochemical properties and structural characterization. Langmuir 1986, 2, 239-244.

5. Li, T.; Weaver, M.J. Intramolecular electron transfer at metal surfaces. 4. Dependence of tunneling probability upon donor-acceptor separation distance. J. Am. Chem. Soc. 1984, 106, 6107-6108.

6. Roberts, G.G. An applied science perspective of Langmuir-Blodgett films. Advan. Phys. 1985, 34, 475-512.

7. Broers, A.N.; Pomerantz, M. Rapid writing of fine lines in langmuir-blodgett films using electron beams. Thin Solid Films 1983, 99, 323-329.

8. Fariss, G.; Lando, J.; Rickert, S. Electron beam resists produced from monomer-polymer Langmuir-Blodgett films. Thin Solid Films 1983, 99, 305-315.

9. Wang, X.; Hu, W.; Ramasubramaniam, R.; Bernstein, G.H.; Snider, G.; Lieberman, M. Formation, characterization, and Sub-50-nm patterning of organosilane monolayers with embedded disulfide bonds: An engineered self-assembled monolayer resist for electron-beam lithography. Langmuir 2003, 19, 9748-9758.

10. Denis, F.A.; Hanarp, P.; Sutherland, D.S.; Gold, J.; Mustin, C.; Rouxhet, P.G.; Dufrene, Y.F. Protein adsorption on model surfaces with controlled nanotopography and chemistry. Langmuir 2002, 18, 819-828.

11. Bourgoin, J.-P.; Doublet, F.; Palacin, S.; Vandevyver, M. High in-plane anisotropy in phthalocyanine LB films. Langmuir 1996, 12, 6473-6479.

12. Sauer, T.; Arndt, T.; Batchelder, D.N.; Kalachev, A.A.; Wegner, G. The structure of Langmuir Blodgett films from substituted phthalocyaninato-polysiloxanes. Thin Solid Films 1990, 187, 357-374. 
13. Cook, M.J.; Mayes, D.A.; Poynter, R.H., Spectroscopic monitoring of thermally induced molecular reorganisations within spin-coated and Langmuir - Blodgett films of mesogenic phthalocyanines. J. Mater. Chem., 1995, 5, 2233-2238.

14. Fujiki, M.; Tabei, H.; Kurihara, T. In-plane dichroisms of phthalocyanine Langmuir-Blodgett films. Langmuir 1988, 4, 1123-1128.

15. Lu, X.; Hipps, K.W.; Wang, X.D.; Mazur, U. Scanning tunneling microscopy of metal phthalocyanines: d7 and d9 cases. J. Am. Chem. Soc. 1996, 118, 7197-7202.

16. Vukusic, P.S.; Sambles, J.R. Cobalt phthalocyanine as a basis for the optical sensing of nitrogen dioxide using surface plasmon resonance. Thin Solid Films 1992, 221, 311-317.

17. Ulman, A. An Introduction to Ultrathin Organic Films: From Langmuir-Blodgett Films to SelfAssembly. Academic Press: San Diego, CA, USA, 1991.

18. Whitesides, G.M.; Laibinis, P.E. Wet chemical approaches to the characterization of organic surfaces: self-assembled monolayers, wetting, and the physical-organic chemistry of the solidliquid interface. Langmuir 1990, 6, 87-96.

19. Bain, C.D.; Troughton, E.B.; Tao, Y.T.; Evall, J.; Whitesides, G.M.; Nuzzo, R.G., Formation of monolayer films by the spontaneous assembly of organic thiols from solution onto gold. J. Am. Chem. Soc. 1989, 111, 321-335.

20. Lee, H.; Kepley, L.J.; Hong, H.G.; Mallouk, T.E. Inorganic analogs of Langmuir-Blodgett films: Adsorption of ordered zirconium 1,10-decanebisphosphonate multilayers on silicon surfaces. $J$. Am. Chem. Soc. 1988, 110, 618-620.

21. Evans, S.D.; Ulman, A.; Goppert-Berarducci, K.E.; Gerenser, L.J. Self-assembled multilayers of .omega.-mercaptoalkanoic acids: selective ionic interactions. J. Am. Chem. Soc. 1991, 113, 5866-5868.

22. Wang, X.; Lieberman, M. Zirconium phosphonate monolayers with embedded disulfide bonds. Langmuir 2003, 19, 7346-7353.

23. Kim, Y.-G.; Kim, J.; Ahn, H.; Kang, B.; Sung, C.; Samuelson, L.A.; Kumar, J. Molecular assembly by sequential ionic adsorption of nanocrystalline $\mathrm{TiO}_{2}$ and a conjugated polymer. $J$. Macromol. Sci. Part A 2003, 40, 1307-1316.

24. Rojas, O.J.; Ernstsson, M.; Neuman, R.D.; Claesson, P.M. Effect of polyelectrolyte charge density on the adsorption and desorption behavior on mica. Langmuir 2002, 18, 1604-1612.

25. Coupe, B.; Evangelista, M.E.; Yeung, R.M.; Chen, W. Surface modification of poly(tetrafluoroethylene-co-hexafluoropropylene) by adsorption of functional polymers. Langmuir 2001, 17, 1956-1960.

26. Pakula, M.; Biniak, S.; Swiatkowski, A. Chemical and electrochemical studies of interactions between iron(III) ions and an activated carbon surface. Langmuir 1998, 14, 3082-3089.

27. Cheng, L.; Niu, L.; Gong, J.; Dong, S. Electrochemical growth and characterization of polyoxometalate-containing monolayers and multilayers on alkanethiol monolayers selfassembled on gold electrodes. Chem. Mater. 1999, 11, 1465-1475.

28. Dambies, L.; Guimon, C.; Yiacoumi, S.; Guibal, E. Characterization of metal ion interactions with chitosan by X-ray photoelectron spectroscopy. Colloid Surf. A 2000, 177, 203-214. 
29. Meng, L.; Hu, L.; Chen, Y.; Du, C.; Wang, Y. Copolymeric network crown ether resins with pendent functional group: Synthesis and adsorption for metal ions. J. Appl. Polym. Sci. 2000, 76, 1457-1465.

30. Brizzolara, R.A. Adsorption of alginic acid to titanium investigated using X-ray photoelectron spectroscopy and atomic force microscopy. Surf. Interface Anal. 2002, 33, 351-360.

31. Agasi, L.; Berry, F.J.; Carbucicchio, M.; Marco, J.; Mortimer, M.; Vetel, F. X-Ray absorption and photoelectron spectroscopic investigation of vanadium interaction with $\mathrm{NH}^{4+}$ - and $\mathrm{Eu}^{3+}$ exchanged zeolite-Y following calcination and steam treatment. J. Mater. Chem., 2002, 12, 3034-3038.

32. Gier, S.; Johns, W.D. Heavy metal-adsorption on micas and clay minerals studied by X-ray photoelectron spectroscopy. Appl. Clay Sci. 2000, 16, 289-299.

33. Rieke, P.C.; Tarasevich, B.J.; Wood, L.L.; Engelhard, M.H.; Baer, D.R.; Fryxell, G.E.; John, C.M.; Laken, D.A.; Jaehnig, M.C. Spatially resolved mineral deposition on patterned selfassembled monolayers. Langmuir 1994, 10, 619-622.

34. Coda, M.E.; Du, H.; Bhandarkar, S. Selected-area sol-gel deposition of barium strontium titanate thin films on thermally oxidized silicon through mediation of self-assembled monolayers. Supramol. Sci. 1997, 4, 43-50.

35. Inumaru, K.; Inoue, Y.; Kakii, S.; Nakano, T.; Yamanaka, S. Organic - inorganic cooperative molecular recognition in nanostructure of alkyl-grafted MCM-41. Chem. Lett. 2003, 32, 1110-1112.

36. Cauvel, A.; Brunel, D.; Garrone, F.D.R.; Fubini, B. Hydrophobic and hydrophilic behavior of micelle-templated mesoporous silica. Langmuir 1997, 13, 2773-2778.

37. Zhang, J.; Xu, X.; Chen, J.; Kang, E.-T. Covalent attachment of polymer thin layers to selfassembled monolayers on gold surface by graft polymerization. Thin Solid Films 2002, 413, 76-84.

38. Fustin, C.-A.; Glasser, G.; Spiess, H.W.; Jonas, U. Site-selective growth of colloidal crystals with photonic properties on chemically patterned surfaces. Adv. Mater. 2003, 15, 1025-1028.

39. Huang, Z.; Wang, P.-C.; MacDiarmid, A.G.; Xia, Y.; Whitesides, G. Selective deposition of conducting polymers on hydroxyl-terminated surfaces with printed monolayers of alkylsiloxanes as templates. Langmuir 1997, 13, 6480-6484.

40. Cant, N.E.; Critchley, K.; Zhang, H.-L.; Evans, S.D. Surface functionalisation for the selfassembly of nanoparticle/polymer multilayer films. Thin Solid Films 2003, 426, 32-39.

41. Lee, I.; Wool, R.P. Controlling amine receptor group density on aluminum oxide surfaces by mixed silane self assembly. Thin Solid Films 2000, 379, 94-100.

42. Bruinsma, G.M.; Mei, H.C.; Busscher, H.J. Bacterial adhesion to surface hydrophilic and hydrophobic contact lenses. Biomaterials 2001, 22, 3217-3224.

43. Deval, J.; Umali, T.A.; Spencer, B.L.; Lan, E.H.; Dunn, B.; Ho, C.-M. Reconfigurable hydrophobic/hydrophilic surfaces based on self-assembled monolayers. Mater. Res. Soc. Sym. Proc. 2003, 774, 203.

44. Papra, A.; Bernard, A.; Juncker, D.; Larsen, N.B.; Michel, B.; Delamarche, E. Microfluidic networks made of poly(dimethylsiloxane), $\mathrm{Si}$, and $\mathrm{Au}$ coated with polyethylene glycol for patterning proteins onto surfaces. Langmuir 2001, 17, 4090-4095. 
45. Tangpasuthadol, V.; Pongchaisirikula, N.; Hove, V.P. Surface modification of chitosan films: Effects of hydrophobicity on protein adsorption. Carbohydr. Res. 2003, 338, 937-942.

46. Shirahata, N.; Yonezawa, T.; Miura, Y.; Kobayashi, K.; Koumoto, K. Patterned adsorption of protein onto a carbohydrate monolayer immobilized on Si. Langmuir 2003, 19, 9107-9109.

47. More, S.D.; Hudecek, J.; Urisu, T. Hydrophobic/hydrophilic interactions of cytochrome c with functionalized self-assembled monolayers on silicon. Surf. Sci. 2003, 532-535, 993-998.

48. Clark, S.L.; Hammond, P.T. The Role of secondary interactions in selective electrostatic multilayer deposition. Langmuir 2000, 16, 10206-10214.

49. Hempenius, M.A.; Péter, M.; Robins, N.S.; Kooij, E.S.; Vancso, G.J. Water-soluble poly(ferrocenylsilanes) for supramolecular assemblies by Layer-by-Layer deposition. Langmuir 2002, 18, 7629-7634.

50. Sennerfors, T.; Bogdanovic, G.; Tiberg, F. Formation, chemical composition, and structure of polyelectrolyte nanoparticle multilayer films. Langmuir 2002, 18, 6410-6415.

51. Lent, C.S.; Tougaw, P.D.; Porod, W.; Bernstein, G.H. Quantum cellular automata. Nanotechnology 1993, 4, 49-57.

52. Lent, C.S.; Tougaw, P.D. Lines of interacting quantum-dot cells: A binary wire. J. Appl. Phys. 1993, 74, 6227-6233.

53. Lent, C.; Tougaw, P.; Porod, W. PhysComp 94: Proceedings of the Workshop on Physics and Computing. IEEE Computer Society Press: 1994.

54. Orlov, A.O.; Amlani, I.; Bernstein, G.H.; Lent, C.S.; Snider, G.L. Realization of a functional cell for quantum-dot cellular automata. Science 1997, 277, 928-930.

55. Creutz, C.; Taube, H. Direct approach to measuring the Franck-Condon barrier to electron transfer between metal ions. J. Am. Chem. Soc. 1969, 91, 3988-3989.

56. Creutz, C.; Taube, H. Preparation and studies of di-nitrogen decaaquodiruthenium(II) fluoroborate. Inor. Chem. 1971, 10, 2664-2667.

57. Creutz, C.; Taube, H. Binuclear complexes of ruthenium ammines. J. Am. Chem. Soc. 1973, 95, 991-1354.

58. Tom, G.M.; Creutz, C.; Taube, H. Mixed valence complexes of ruthenium ammines with 4,4'bipyridine as bridging ligand. J. Am. Chem. Soc. 1974, 96, 7827-7829.

59. Lent, C.S. Bypassing the transistor paradigm. Science 2001, 288, 1597-1599.

60. Lieberman, M.; Chellamma, S.; Varughese, B.; Wang, Y.; Lent, C.S.; Bernstein, G.H.; Snider, G.L.; Peiris, F.C. Quantum-Dot Cellular Automata at a Molecular Scale. Molecular Electronics II, Ann. N.Y. Acad. Sci. 2002, 960, 225-239.

61. Lent, C.S.; Isaksen, B.; Lieberman, M. Molecular Quantum-Dot Cellular Automata. J. Am. Chem. Soc. 2003, 125, 1056-1063.

62. Varughese, B.; Chellamma, S.; Lieberman, M. XPS study of self-assembly of ruthenium dimers $\left[\left((\mathrm{acac})_{2} \mathrm{Ru}\right)_{2} \mathrm{bptz}\right]^{0,+}$ on hydrophobic and hydrophilic SAMs. Langmuir 2002, 18, 7964-7970.

63. Wang, Z.-S.; Ebina, Y.; Takada, K.; Watanabe, M.; Sasaki, T. Inorganic multilayer assembly of titania semiconductor nanosheets and Ru complexes. Langmuir 2003, 19, 9534-9537.

64. Monjushiro, H.; Harada, K.; Haga, M.-A. Characterization of Langmuir monolayers of the amphiphilic Ru complex at the air/water interface by ultraviolet photoelectron yield spectroscopy. Langmuir 2003, 19, 9226-9230. 
65. Cox, L.C. Nanocomposite multilayer film of a ruthenium metallodendrimer and a Dawson-Type polyoxometalate as a bifunctional electrocatalyst. Chem. Mater. 2002, 14, 6-8.

66. Cassagneau, T.; Fendler, J.H.; Johnson, S.A.; Mallouk, T.E. Self-assembled diode junctions prepared from a ruthenium tris(bipyridyl) polymer, n-Type $\mathrm{TiO}_{2}$ nanoparticles, and graphite oxide sheets. Adv. Mater. 2000, 12, 1363-1366.

67. Chidsey, C.E.D.; Bertozzi, C.R.; Putvinski, T.M.; Mujsce, A.M. Coadsorption of ferroceneterminated and unsubstituted alkanethiols on gold: Electroactive self-assembled monolayers. $J$. Am. Chem. Soc. 1990, 112, 4301-4306.

68. Iler, R. The Chemistry of Silica. Wiley-Interscience Publications: NY, USA, 1979.

69. Wang, Y.; Lieberman, M. Growth of ultrasmooth octadecyltrichlorosilane self-assembled monolayers on $\mathrm{SiO}_{2}$. Langmuir 2003, 19, 1159-1167.

70. Citrin, P.H.; Ginsbeg, A.P. X-ray photoemission from the Creutz-Taube mixed valence complex: A reassessment. J. Am. Chem. Soc. 1981, 103, 3673-3679.

71. Shepherd, R.E.; Proctor, A.; Henderson, W.W.; Myser, T.K. Assessment of the .pi.-acceptor capability of selected ligands based on the photoelectron spectra of ruthenium ammine complexes. Inorg. Chem. 1987, 26, 2440-2444.

72. Auburn, P.R.; Dodsworth, E.S.; Haga, M.; Liu, W.; Nevin, W.A.; Lever, A.B.P. Bis(dioxolene)bis(pyridine)ruthenium redox series. Inorg. Chem. 1991, 30, 3502-3512.

73. Gassman, P.G.; Winter, C.H. Preparation, electrochemical oxidation, and XPS studies of unsymmetrical ruthenocenes bearing the pentamethylcyclopentadienyl ligand. J. Am. Chem. Soc. 1988, 110, 6130-6135.

74. Moulder, J.; Stickle, W.; Sobol, P.; Bomben, K. Handbook of X-ray Photoelectron Spectroscopy. Physical Electronics Division, Perkin-Elmer: Eden Prairie, MN, USA, 1992-1995.

(C) 2009 by the authors; licensee Molecular Diversity Preservation International, Basel, Switzerland. This article is an open-access article distributed under the terms and conditions of the Creative Commons Attribution license (http://creativecommons.org/licenses/by/3.0/). 